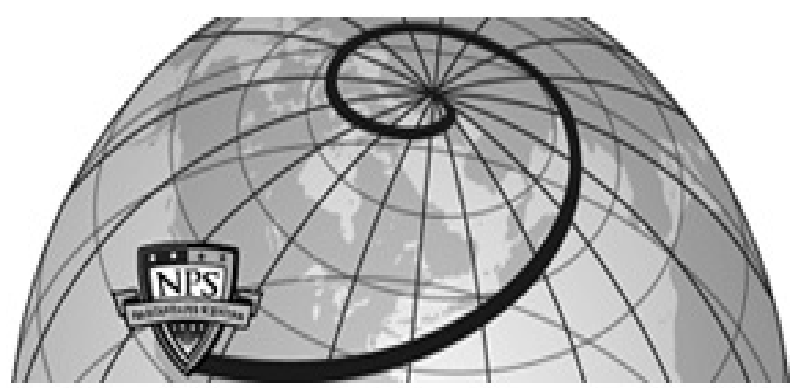

Calhoun: The NPS Institutional Archive DSpace Repository

\title{
Lean Six Sigma in Healthcare: Combating the Military's Escalating Pharmacy Costs
}

Apte, Uday; Kang, Keebom

https://hdl.handle.net/10945/33791

This publication is a work of the U.S. Government as defined in Title 17, United States Code, Section 101. Copyright protection is not available for this work in the United States.

Downloaded from NPS Archive: Calhoun

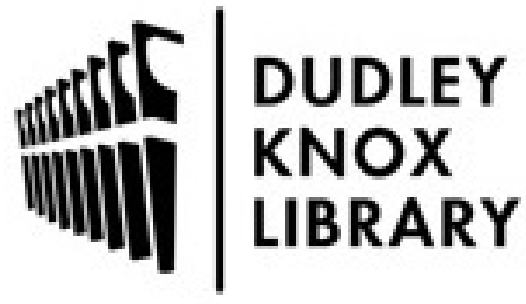

http://www.nps.edu/library
Calhoun is the Naval Postgraduate School's public access digital repository for research materials and institutional publications created by the NPS community. Calhoun is named for Professor of Mathematics Guy K. Calhoun, NPS's first appointed -- and published -- scholarly author.

Dudley Knox Library / Naval Postgraduate School 411 Dyer Road / 1 University Circle Monterey, California USA 93943 
NPS-HR-09-016

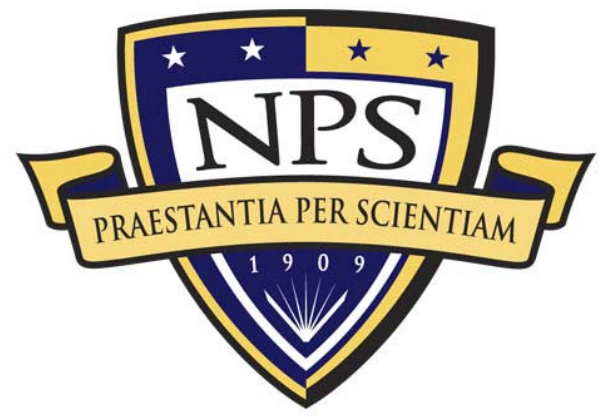

\section{MANPOWER, PERSONNEL, TRAINING $\&$ EDUCATION RESEARCH SPONSORED REPORT SERIES}

\section{Lean Six Sigma in Healthcare: \\ Combating the Military's Escalating Pharmacy Costs}

30 April 2009

by

Dr. Keebom Kang, Associate Professor, and

Dr. Uday M. Apte, Professor

Graduate School of Business \& Public Policy

Naval Postgraduate School

Approved for public release, distribution is unlimited.

Prepared for: Naval Postgraduate School, Monterey, California 93943 
The research presented in this report was supported by the Acquisition Chair of the Graduate School of Business \& Public Policy at the Naval Postgraduate School.

To request Defense Manpower, Personnel, Training \& Education Research or to become a research sponsor, please contact:

Attn: James B. Greene, RADM, USN, (Ret)

Acquisition Chair

Graduate School of Business and Public Policy

Naval Postgraduate School

555 Dyer Road, Room 332

Monterey, CA 93943-5103

Tel: (831) 656-2092

Fax: (831) 656-2253

e-mail: ibgreene@nps.edu

Copies of the Sponsored Research Reports may be printed from our website: www.acquisitionresearch.org 


\section{Abstract}

Healthcare costs throughout the United States are on the rise, drawing increased scrutiny from government officials and Congress. The cost of pharmacy operations and pharmaceuticals is growing at a rate that is alarmingly higher than that of the total cost of military healthcare itself. Recent congressional legislation has essentially given the Department of Defense the ultimatum to cut costs for beneficiaries wherever possible, or risk having benefits arbitrarily cut by Congress. In the face of this possibility, cutting costs through better business practices must be explored, particularly within the area of pharmacy operations. This project explores the potential cost savings that can be realized by implementing Lean Six Sigma (LSS) methodology in the pharmacy operations of the DoD Medical Treatment Facilities (MTF). This research proves that implementing Lean Six Sigma methodology will improve military pharmacy operations, often at little cost, while realizing significant savings and increased customer satisfaction.

Keywords: Healthcare costs, pharmacy operations, pharmaceuticals, Lean Six Sigma (LSS), DoD Medical Treatment Facilities (MTF) 
THIS PAGE INTENTIONALLY LEFT BLANK 


\section{Acknowledgements}

This research was sponsored by the Office of the Chief of Naval Personnel (N1). We wish to thank Mr. Wayne Wagner, Senior Strategy Analyst N1Z, for supporting this project. Captain Andy Nuce (USA), LT Lidya Robinson (USN), Captain Thomas Sikora (USMC) participated in this project as part of their MBA report. Dr. Susan Heath helped supervise the MBA report. 
THIS PAGE INTENTIONALLY LEFT BLANK 


\section{About the Authors}

Professor Keebom Kang is the Chair of the Operations and Logistics Management Program at the Graduate School of Business and Public Policy of the Naval Postgraduate School in Monterey, California. He also has joint appointments with the Systems Engineering Department and the International Defense Acquisition and Resource Management (IDARM) Program at the Naval Postgraduate School. He received his $\mathrm{PhD}$ in Industrial Engineering from Purdue University, an MS in Operations Research from the University of Texas at Austin, and a BS in Industrial Engineering from Seoul National University. He joined the faculty of the Naval Postgraduate School in 1988, and he teaches supply chain, logistics engineering and computer simulation modeling courses. His research interests are in the areas of logistics and simulation modeling in various military applications.

Prior to joining the NPS faculty, he was on the faculty of the Industrial Engineering Department at the University of Miami, Coral Gables, Florida (19831988). He had held visiting professor positions at Syracuse University (Summer, 1985), Georgia Institute of Technology (Fall, 2003), Asian Institute of Technology in Thailand (Winter, 2004), and Pohang Institute of Science and Technology in Korea (Spring, 2004). Dr. Kang has taught IDARM courses in military logistics and supply chain management courses in many NATO and allied countries.

Dr. Kang has published many theoretical and applied papers in Operations Research, IEEE Transactions in Communications, IIE Transactions, Telecommunication Management, Naval Logistics Quarterly, and other technical journals and conference proceedings. He has been involved in organizing and coordinating many international conferences. He was the Co-editor of the 1995 Winter Simulation Conference Proceedings and the program chair for the 2000 Winter Simulation Conference held in Orlando, Florida in December 2000. He received outstanding service awards (1995 and 2000) from the board of the Winter Simulation Conference and also from ACM (Association for Computing Machinery) in 2001. He is currently Associate Editor of Naval Research Logistics and an editorial board member for IIE Transactions. He also served as an associate editor for IMA Journal of Mathematics for Management Science, an associate editor for IIE Transactions Special Issue on Computer Simulation, and as a referee for many professional journals including Operations Research, Management Science, and Naval Logistics Research.

Dr. Uday Apte is a Professor of Operations Management at the Graduate School of Business and Public Policy, Naval Postgraduate School, Monterey, California. Before joining the NPS faculty, Dr. Apte taught at The Wharton School, University of Pennsylvania, Philadelphia, and at the Cox School of Business, Southern Methodist University, Dallas. He is experienced in teaching a range of operations management and management science courses in the Executive and Full-time MBA 
programs as well as the business undergraduate programs. His earlier education includes a B. Tech. in Chemical Engineering from the Indian Institute of Technology, Bombay, India, an MBA from the Asian Institute of Management, Manila, Philippines, and a PhD in Decision Sciences from The Wharton School, University of Pennsylvania, Philadelphia.

Dr. Apte is currently serving as the Vice President for Colleges, Production and Operations Management Society (POMS). In the past he has served as the founder and President of the POMS College of Service Operations, as a board member of POMS, and as guest editor of Production and Operations Management journal. Prior to his career in academia, Dr. Apte worked for over ten years in managing operations and information systems in the financial services and utility industries. Since then, he has consulted with several major US corporations and international organizations. His recent consulting engagements have focused on process improvement using Lean Six Sigma and development of operations strategy.

Dr. Apte's research interests include managing service operations, globalization of information-intensive services, supply chain management, and technology management. He has published over 40 research articles, five of which have won awards from professional societies. His research articles have been published in prestigious journals including Management Science, Interfaces, Production and Operations Management, Journal of Operations Management, Decision Sciences, IIE Transactions, Interfaces, and MIS Quarterly. He has co-authored two books, Manufacturing Automation and Managing in the Information Economy. 
NPS-HR-09-016

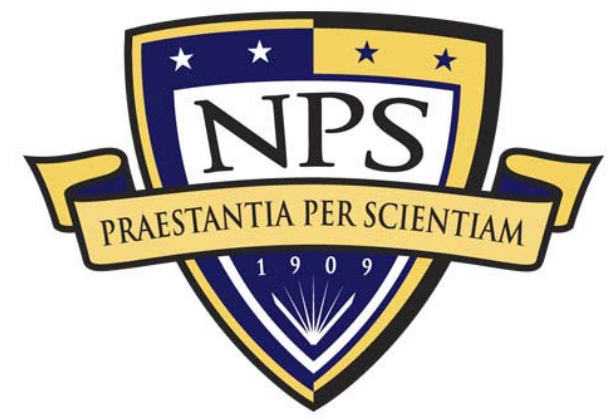

\section{MANPOWER, PERSONNEL, TRAINING $\&$ EDUCATION RESEARCH SPONSORED REPORT SERIES}

\section{Lean Six Sigma in Healthcare: \\ Combating the Military's Escalating Pharmacy Costs}

30 April 2009

by

Dr. Keebom Kang, Associate Professor, and

Dr. Uday M. Apte, Professor

Graduate School of Business \& Public Policy

Naval Postgraduate School 
THIS PAGE INTENTIONALLY LEFT BLANK 


\section{Table of Contents}

List of Acronyms and Abbreviations ..........................................................

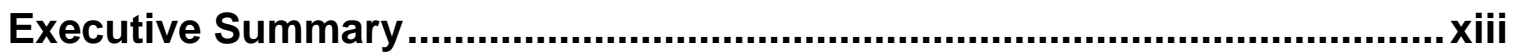

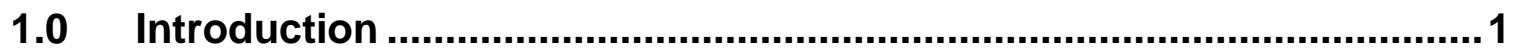

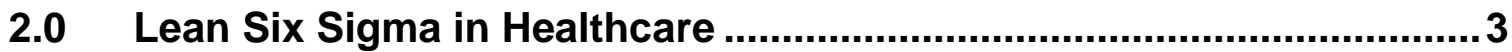

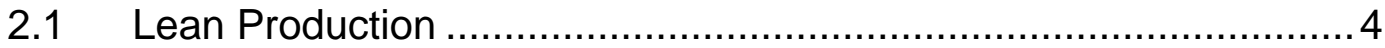

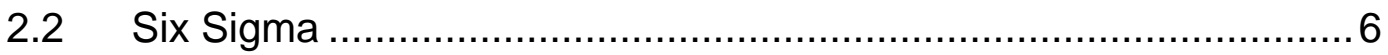

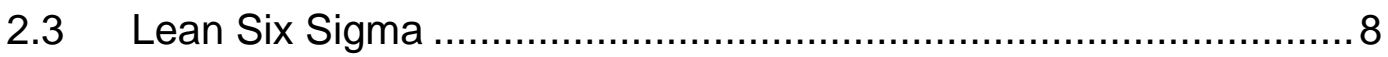

2.4 Lean Six Sigma Applications in Healthcare ................................ 8

2.5 Lean Six Sigma Applications in Healthcare Facilities .................. 10

2.6 Lean Six Sigma Applications in Dispensing Practices .................. 11

3.0 The Pharmacy Cost Structure ........................................................ 15

3.1 Congressional Legislation .................................................... 15

3.2 The Pharmacy Costs ............................................................ 17

4.0 Improving Pharmacy Operations with Lean Six Sigma Tools ............23

4.1 Travis AFB Pharmacies: An Overview....................................23

4.2 Application of Selected LSS Tools...........................................26

4.3 Process Improvement at Travis AFB Pharmacies ............................ 36

4.4. Defense Language Institute (DLI) Pharmacy ................................43

4.5 Balboa Naval Medical Center San Diego Pharmacy ......................... 46

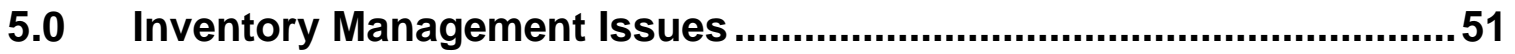

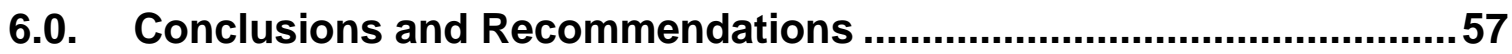




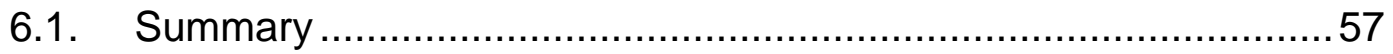

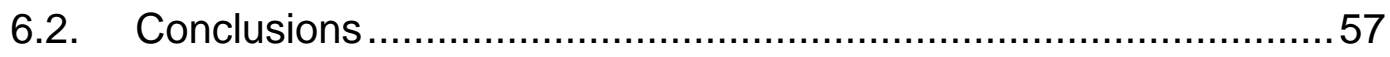

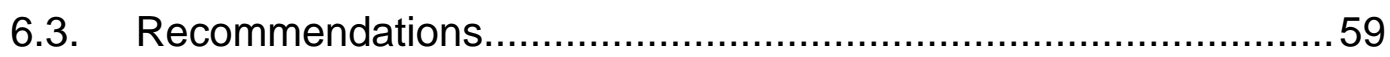

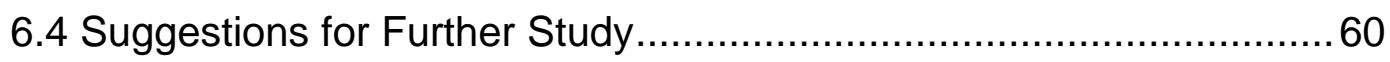

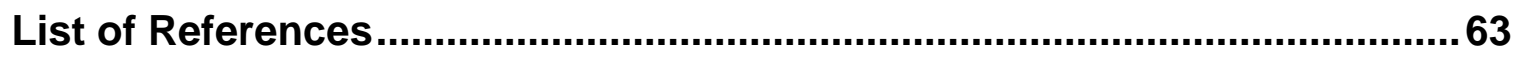




\section{List of Acronyms and Abbreviations}

$\begin{array}{ll}\text { AFB } & \text { AIR FORCE BASE } \\ \text { CBO } & \text { CONGRESSIONAL BUDGET OFFICE } \\ \text { CHCS } & \text { COMPOSITE HEALTHCARE SYSTEM } \\ \text { CMOP } & \text { CONSOLIDATED MAIL ORDER PHARMACY } \\ \text { CTQ } & \text { CRITICAL TO QUALITY } \\ \text { DLA } & \text { DEFENSE LOGISTICS AGENCY } \\ \text { DLI } & \text { DEFENSE LANGUAGE INSTITUTE } \\ \text { DMAIC } & \text { DEFINE, MEASURE, ANALYZE, IMPROVE, CONTROL } \\ \text { DMLSS } & \text { DEFENSE MEDICAL LOGISTICS STANDARD SUPPORT } \\ \text { DOD } & \text { DEPARTMENT OF DEFENSE } \\ \text { FSS } & \text { FEDERAL SUPPLY SYSTEM } \\ \text { LSS } & \text { LEAN SIX SIGMA } \\ \text { MAR } & \text { MEDICATION ADMINISTRATION RECORDS } \\ \text { MTF } & \text { MEDICAL TREATMENT FACILITY } \\ \text { O\&S } & \text { OPERATIONS AND SUPPORT } \\ \text { OMB } & \text { OFFICE OF MANAGEMENT AND BUDGETING } \\ \text { OPM } & \text { OFFICE OF THE PERSONNEL MANAGEMENT } \\ \text { PDTS } & \text { PATIENT DATA TRANSACTION SYSTEM } \\ \text { POE } & \text { PROVIDER ORDER ENTRY } \\ \text { PTO } & \text { PHARMACY TYPE ORDER } \\ \text { RX } & \text { PHARMACEUTICAL PRESCRIPTION } \\ \text { SIPOC } & \text { SUPPLIES, INPUTS, PROCESS, OUTPUT, CUSTOMER } \\ \text { TFL } & \text { TRICARE FOR LIFE } \\ \text { TMOP } & \text { TRICARE MAIL ORDER PHARMACY PROGRAM } \\ \text { TRICARE } & \text { TRI-SERVICE HEALTHCARE SYSTEM } \\ & \end{array}$


THIS PAGE INTENTIONALLY LEFT BLANK 


\section{Executive Summary}

Healthcare costs throughout the United States are on the rise, drawing increased scrutiny from government officials and Congress. The cost of pharmacy operations and pharmaceuticals is growing at a rate that is alarmingly higher than that of the total cost of military healthcare itself. Recent congressional legislation has essentially given the DoD the ultimatum to cut costs for beneficiaries wherever possible, or risk having benefits arbitrarily cut by Congress. In the face of this possibility, cutting costs through better business practices must be explored, particularly within the area of pharmacy operations. This project explores the potential cost savings that might be realized by implementing Lean Six Sigma (LSS) methodology in the pharmacy operations of the DoD Medical Treatment Facilities (MTF). This research proves that implementing Lean Six Sigma methodology can improve military pharmacy operations, often at little cost, while realizing significant savings and increased customer satisfaction.

In this research project, we visited three MTF pharmacies located in Defense Language Institute, Travis Air Force Base (AFB) and Naval Medical Center San Diego (Balboa). We discuss below our findings, which can potentially improve pharmacy operations for better customer service and reduced healthcare cost for the DoD.

1. Good inventory management practice should be implemented throughout the DoD pharmacies We have observed a lack of scientific pharmaceutical inventory management. Newly-arrived pharmaceutical items were stacked on top of the current inventory on the shelf, increasing the amount of expired medications. No information system was available to keep track of the shelf life of each drug. The government credit card return amount at the Travis AFB pharmacy was more than $\$ 1$ million a year for expired medications. This translated to over $\$ 4.2$ million per year of pharmaceuticals turned in (or $16 \%$ of the annual expenditure to purchase drugs), using a generous rate of 25 cents per dollar given for all returns to a pharmaceutical return company. The pharmaceutical returns showed the need for good inventory management for economic order quantity, asset visibility, and stock rotation, which could contribute to savings of more than the $\$ 4.2$ million worth of turned-in pharmaceuticals from one mediumsize MTF pharmacy. If good inventory management practice is 
implemented throughout the DoD pharmacies, the cost savings would be significant.

Stock rotation can be done through the prime vendor. This should be part of the contract with the prime vendor-similar to a vendor-managed inventory (VMI) system commonly practiced in the commercial sector. The prime vendor will replace the items after a certain period of time, long before the shelf-expiration date. The prime vendor, on the other hand, can find demand for the replaced items with other customers by using its vast distribution network. The improvement can be immediately realized if the inventory clerk strictly enforces first-in-first-out (FIFO) inventory policy. In fact, this can be done with practically no cost and with minimal training of the pharmacy clerks.

2. Manpower issues also deserve closer examination. Calculation of the optimal number of employees in each pharmacy is a very complicated problem. Each pharmacy has a different size, number of clientele and layout. Different pharmacies and hospitals also have different compositions of employees on their respective staff. We note that some pharmacies carry a larger composition of contracted employees than General Scale (GS) employees, at a significantly higher cost. In addition, the GS employees carry still higher costs to these facilities relative to their active duty counterparts. Determining the optimal number of employees and the ideal employee composition in terms of contracted employees, GS employees, and active duty personnel is a complex issue with many considerations. For example, one should also take into account the expertise and experience of these different employee types. In addition, the factors such as the routine 2-3 year rotation of active duty personnel, the need for additional training, etc., must also be taken into account.

3. Though it is a test program, Balboa's use of mail delivery of pharmaceuticals, outsourced to the Consolidated Mail Outpatient Pharmacy (CMOP) program, appears to contribute significantly not only to greater convenience to the customer but also to cost savings. While similar programs exist elsewhere, limited results have been documented in terms of cost-benefit analysis. There may be considerable benefits to measuring and analyzing Balboa's perceived successes in cost savings and enforcing home delivery programs to the DoD pharmacies as a whole. More comprehensive research should be done to study the benefits of a mail-order system for refill orders.

4. It should be kept in mind that no process improvement can be achieved overnight. While simple redesign of pharmacy layout or adding a printer can improve productivity, more sophisticated implementation requires technical expertise. The Naval Postgraduate School research team is willing to help the DoD improve pharmacy operations and reduce 
healthcare cost by providing technical consultation and training. Finally, the actual implementation of continuous process improvement cannot really be undertaken without the employee buy-in. The DoD must provide its employees with suitable training and an incentive system so that they can voluntarily participate in the continuous process improvement efforts. As with any organization, support from leadership and open communication is essential to process improvement.

5. Improving healthcare operations is simply too large and too important of a topic to ignore and is worthy of numerous studies. The current study, which addresses pharmacy operations at three sites, has simply scratched the surface of this issue. 
THIS PAGE INTENTIONALLY LEFT BLANK 


\section{$1.0 \quad$ Introduction}

Rising healthcare costs are a fact of life for US citizens, both in and out of the uniform. Military personnel costs are skyrocketing, and the biggest percentage of this growth is coming from the military healthcare system. The legislative actions concerning TRICARE for Life (TFL) and extended reservist eligibility for TRICARE have added to the costs and have made the current military healthcare situation even more challenging. The Congressional Budget Office (CBO) has recently forecasted growth of $3 \%$ in healthcare costs, with an anticipated deficit to the system of approximately $\$ 38.4$ billion (CBO, 2007). Hence, as good stewards of taxpayer dollars, it is critically important that the military begin taking a serious look at streamlining healthcare operations and containing the associated costs.

The purpose of this study is to use Lean Six Sigma (LSS) methodology to study operations within the pharmacies of Medical Treatment Facilities (MTF) to improve operations and realize quantifiable benefits in terms of improved efficiency in the use of manpower, facilities, and pharmaceutical cost savings. Since 2001 (post 9/11) and the institution of TFL, pharmacies have seen significant increases in the number of customers and, subsequently, have seen increased costs. In fact, the cost of pharmacies is the single biggest line item on any hospital budget. Congress has mandated using civilian business organizations as benchmarks to improve efficiency in the hopes of saving money within the military. Previous work done in analyzing military pharmacies has studied benchmarking (Coon, 2006) and leastcost procurement methods (Henning, 2008); however, neither of these studies have evaluated possible efficiency and financial benefits that could be reaped from utilizing LSS methodology in military pharmacies.

The MBA project (Nuce, Robinson, \& Sikora, 2008) completed as a part of this research involved the utilization of LSS tools to improve small, medium and large pharmacy operations of military medical hospitals from different branches of military service. The facilities studied were the Army Defense Language Institute 
(DLI) medical clinic pharmacy in Monterey, CA; the Travis Air Force Base hospital, which consists of three pharmacies in Fairfield, CA; and the Balboa Naval Medical Center pharmacy in San Diego, CA.

This report is organized in six sections, including this introductory section. The second section provides an overview of Lean Six Sigma methodology and a short review of prior work involving the application of LSS methodology to healthcare operations. The pharmacy cost structure, including a summary of congressional legislation and policies that have an impact on the military healthcare, are discussed in section three. The fourth section presents the empirical details of our research effort in applying LSS methodology for improving the operations at three military pharmacy locations-the Army Defense Language Institute (DLI), Travis Air Force Base, and the San Diego Naval Base. Section five discusses the important issue of inventory management. Finally, the conclusions and recommendations of the study are presented in section six. 


\subsection{Lean Six Sigma in Healthcare}

Penchant for process improvement is inherent in human nature. Early improvements probably came about through trial and error and took hundreds (if not thousands) of years to become part of the human skill set. However, the fast pace of the modern commercial/industrial economy has given rise to the structured problemsolving methodologies for process improvement that are well understood and can be implemented by all.

Two major approaches for structured problem solving emerged separately in the 20th century and have come to be known as "Lean" and "Six Sigma" methodologies. Lean improvements focus on improving process speed and reducing waste while Six Sigma, like its predecessor Total Quality Management (TQM), focuses on improving quality and reducing process variability. Ironically, Six Sigma and Lean were originally regarded as rival initiatives. Lean enthusiasts noted that Six Sigma paid little attention to anything related to speed and flow while Six Sigma supporters pointed out that Lean failed to address key concepts like customer needs and process variation. To some extent, these are valid arguments. Yet, the arguments were more often used by the practitioners to promote the choice of one versus the other approach. However, today's need for an even higher level of competitiveness than that achieved through implementing either methodology has now convinced practitioners that there is significant benefit to be realized by blending the two and that these two approaches are in fact synergistic. Therefore, in the new millennium, we are witnessing the emergence of Lean Six Sigma (Apte, \& Kang, 2008; George, 2002; Nash, Poling, \& Ward, 2006).

Lean and Six Sigma are two different bodies of knowledge. The Six Sigma deals with locating and eliminating root causes of process problems. The Six Sigma tools, such as the "the five whys," are designed to find the root cause(s) of the problems and build models of cause and effect. The process is then redesigned with the root cause(s) eliminated. 
Lean is different. As popularized by Womack and Jones (2003), the Lean roadmap is one of successive refinements to improve the overall process through the following steps (Apte \& Goh, 2004):

- Specify value in the eyes of the customer,

- Identify the value stream and eliminate waste,

- Make value flow at the pull of the customer,

- Involve and empower employees, and

- Continuously improve in the pursuit of perfection.

Since Lean Six Sigma is a synergistic blending of Lean Production and Six Sigma methodologies, we will present a brief overview of these two methodologies.

\subsection{Lean Production}

Lean can be defined as a set of principles and tools that help us eliminate process activities that don't add value and create "flow" in a process (Dennis, 2002). A Lean process is defined as one that uses only the absolute minimum of resources to add value to the service or product. Lean manufacturing can also be viewed as a management philosophy focusing on reduction of the eight types of wastes (human talent, over-production, waiting time, transportation, processing, inventory, motion and scrap) in manufacturing or service processes (Wikipedia, 2009). By eliminating waste, quality is improved and production time and cost are reduced. Lean "tools" include continuous process improvement, "pull" production process and mistakeproofing. Lean, as a management philosophy, is also focused on creating a better workplace through the Toyota principle of "respect for humanity."

Origins of Lean Production can be traced to the Scientific Management principles of Frederic Taylor (1911) and to the practical genius of Henry Ford (Levinson, 2002). But the principles of Lean Production were more fully embodied in its recent incarnations: Just-in-Time Systems and Toyota Production System. The term Lean Production was coined by Womack, Jones and Roos (1991) in their best 
seller, The Machine that Changed the World. The book chronicles the transitions of automobile manufacturing from craft production to mass production to Lean Production. "Theory of Constraints (TOC)," popularized by Goldratt and Cox (1992) in their novel The Goal, is also typically used in implementing Lean Production. Simply put, TOC involves identification and use of the bottleneck (i.e., the constraint) of the system to set the operational pace of the system's components and achieve a synchronous flow so as to maximize the throughput (i.e., the money-making potential) of the system.

At the heart of Lean is the determination of value. Value is defined as what a customer is willing to pay for form, feature or function. The processes that do not add value are deemed waste. The Lean framework is used as a tool to focus resources and energies on producing the value-added features while identifying and eliminating non-value added activities. Processes in Lean are thought of as value streams. Lead-time reduction and the synchronized, smooth flow of the value streams are the major areas of focus in Lean. Value-stream Mapping helps teams understand the flow of material and information in creating and delivering the product or services being offered to the customer by the organization.

In summary, in its current implementation, the Lean methodology:

- $\quad$ Provides tools for analyzing process flow and delay times at each activity in a process,

- $\quad$ Emphasizes Value-stream Mapping, which centers on the separation of "value-added" from "non-value-added" work with tools to eliminate the root causes of non-valued activities and their cost,

- Uses Theory of Constraints as its integral element to identify bottlenecks and achieve a synchronous flow in the system,

- Recognizes and attempts to eliminate eight types of waste/non-valueadded work including human talent, over-production, waiting time, transportation, processing, inventory, motion and scrap and

- $\quad$ Creates workplace organization through Five S methodology consisting of sort, straighten, sustain, sweep, and standardize. 


\subsection{Six Sigma}

Six Sigma is a management technique that aims to develop and deliver nearperfect products and services. The primary goal of Six Sigma is to improve customer satisfaction (and, thereby, profitability) by reducing and eliminating defects. In this case, the defects may be related to any aspect of customer satisfaction such as product quality and delivery performance. Six Sigma is targeted at reducing variation in business processes. It can also be a great way to permeate the culture of continuous improvement in an organization.

The term "Six Sigma" refers to a statistical construct that measures how far a given process deviates from perfection. Specifically, Six Sigma level of quality refers to a very high level of quality (only 3.4 defects per every million items). A Six Sigma process is commonly interpreted as being at the highest level of quality: virtually all products and business processes are defect-free. It should be noted that most companies today function at only a three or four sigma level and lose $10-15 \%$ of their total revenue due to defects. Thus, a typical company stands to benefit significantly from implementing Six Sigma.

Six Sigma originated in 1986 with the efforts of Bill Smith, a senior engineer and scientist at Motorola (Wikipedia, 2009). It was originally used to improve manufacturing processes at Motorola. The methodology gained industry-wide acceptance in mid-90s when Jack Welch, CEO of GE, successfully launched it within the entire company (General Electric, 2006) and began crediting the billiondollar benefits realized by GE to the use of Six Sigma methodology. For instance, in 1999 alone, GE reported that it saved $\$ 2$ billion using Six Sigma principles. While Six Sigma has its roots in the Total Quality Management (TQM) approach of the 1980 s, today it is much more than that. It is now being used across a wide range of industries including banking, insurance, telecommunications, construction, healthcare and software. 
Six Sigma now has much broader meaning. Simply put, Six Sigma:

- $\quad$ Emphasizes the need to recognize opportunities and eliminate defects as defined by customers,

- $\quad$ Recognizes that process variation hinders the ability to reliably deliver high-quality services,

- $\quad$ Requires data-driven decisions and incorporates a comprehensive set of quality tools under a powerful framework for effective problem solving, and

- $\quad$ Provides a highly prescriptive cultural infrastructure that is effective in obtaining sustainable results.

In any improvement project, utilization of a well-defined improvement procedure is critically important. The most commonly used standard improvement procedure in Six Sigma is DMAIC (Define, Measure, Analyze, Improve and Control). DMAIC is a structured, disciplined, rigorous approach to process improvement, consisting of the five phases in which each phase is linked logically to the previous phase as well as to the next phase. A detailed description of these phases can be found in Stamatis (2004) and Rath \& Strong (2006).

In terms of the tools and techniques used for process improvement, there is only a marginal difference between Six Sigma and the Total Quality Management approaches. But what sets Six Sigma apart from TQM, which is perhaps the most important reason behind the success of Six Sigma, is the establishment of organizational infrastructure for ensuring continuous process improvement. Thus, Six Sigma should be ideally viewed as a management system that integrates strategic objective and measurement systems development and provides the guidance for project prioritization and governance. It is a performance management system to drive a more focused execution of the overall business strategy. The essential premise of the Six Sigma Management System is that there is a leadership team in place whose members are willing and capable of engaging in a disciplined, team-based process of continuously monitoring real-time organizational performance metrics and then taking action in the form of project reviews. The team 
engages in frequent dialogue regarding performance related to customer and market requirements as well as performance related to critical improvement projects. As a result of these efforts, an organization-wide dialogue is created that drives top-tobottom focus on daily execution and a culture of continuous improvement.

\subsection{Lean Six Sigma}

As noted earlier, the process improvement methods of Lean and Six Sigma have been practiced separately for many years. However, in recent years, practitioners have come to realize that the two methodologies are, in fact, dependent on each other for greater success. For example, it is impossible to run a process with minimum waste or at a dependable capacity if individual process steps are highly variable. On the other hand, one can carefully study the complex processes by looking for root causes using elegant statistical techniques and never make improvements in cycle-time or productivity that can be obtained from value-stream analysis.

To the extent that Lean and Six Sigma approaches have their own strengths and weaknesses, the specific action plan to be followed in effectively implementing Lean Six Sigma (for example, Lean followed by Six Sigma or vice versa) is dependent on the nature of the situation at hand. For example, the problems related to accuracy and/or completeness are usually addressed best by the tools of Six Sigma; consequently, those tools should be introduced first. However, if the customer needs quick results and if the problem is related to timeliness or productivity, Lean should be implemented first with an understanding that deep and complex problems will be solved only by the subsequent use of the Six Sigma tools.

\subsection{Lean Six Sigma Applications in Healthcare} In their article, "Lean Six Sigma in Healthcare," Koning, Verver, Heuvel, Bisgaard, and Does (2006) illustrate the use of Lean Six Sigma methodology in the healthcare industry. The article supports the notion that Lean Six Sigma can be used to improve any organizational process regardless of industry. The authors 
reiterate the point that with the increasing cost in healthcare, implementing Lean Six Sigma methodologies is critically important to a healthcare organization in order to provide better healthcare, improve quality, and control healthcare cost increases. There are numerous departments within a hospital that can experience operational inefficiencies. These inefficiencies can be associated with direct medical care delivery processes, pharmacy operations processes, logistical processes and administrative processes, just to name a few.

Koning et al. (2006) discuss the case of a Red Cross hospital in the Netherlands where the management found that Lean Six Sigma methodology provided solutions to many of their existing problems. The article systematically takes us through the five phases of Lean Six Sigma. For example, in the Define phase, the hospital determined that there were numerous problems that needed to be addressed. Their list of problems included shortening length of hospitalization for patients with chronic obstructive pulmonary disease, reducing the level of invoice errors from temporary agencies, revising the terms of payment, allowing parents to stay in rooms with hospitalized children, reducing the requirement for intravenous antibiotics, shortening the preparation time of intravenous medication, and reducing the number of mistakes found on invoices (Koning et al., 2006, p. 7). As the authors state, inefficiencies can be found in any department throughout any hospital ranging from administrative to patient care delivery. The Analysis phase revealed that only $15 \%$ of the invoices were correct. The goal of the hospital was to have a $100 \%$ accuracy regarding invoices. Further analysis found that important signatures were missing in various critical documents, breaks were not logged, recorded hours worked were inaccurate, and incorrect hourly wages were applied, to name a few. It was discovered that the root cause of the problem was the fact that there were differences in the invoices used by various temporary agencies. As part of the Improvement phase, the hospital implemented a standardized worksheet, centralized requests for temporary employees, reduced the number of temporary agencies previously used, and implemented a system that checked invoices for 
accuracy. These changes "resulted in reduced rework and significant cost savings" (Koning et al., 2006, p. 9).

In summary, the article depicts the successful application of Lean Six Sigma methodology in a healthcare setting and supports the idea that along with cost savings, process improvement also results in improved employee morale. The article brings to light the qualitative effects of using Lean Six Sigma methodology, and although morale cannot be measured, it is certainly important to any organization.

\subsection{Lean Six Sigma Applications in Healthcare Facilities} In her article "Using Six Sigma and Lean Methodologies to Improve Operating Room (OR) Throughput," Fairbanks (2007) illustrates the importance of the five phases of Lean Six Sigma (Define, Measure, Analyze, Improve, and Control), by depicting how a hospital in Vermont improved patient throughput by implementing Lean Six Sigma methodology for patients undergoing elective surgery. In the Define phase, the "project began with the perception that surgical procedures could not be scheduled in the OR in a manner that met surgeon or patient needs" (Fairbanks, 2007, p. 75). To help further identify the problem, the project team distributed surveys to the nursing staff and grouped survey responses into major themes. Based on the survey responses, procedural delays were determined to be the major cause of the problem.

In the Measure phase, the use of computer programming was necessary in order to obtain scheduling information from the OR. Charts and graphs were created based on the scheduling information provided by the OR. Using this data along with statistical methods, the information was analyzed to "understand the cause-and-effect relationship in the process or system" (Fairbanks, 2007, p. 77). This allowed the team to determine where improvement efforts could best be applied. An important factor for the Analysis phase is that solutions are based on data rather than on assumptions. 
As with any organization, support from leadership and open communication is essential to process improvement. Specific to this hospital, the Improve phase required that leadership and all healthcare providers continuously maintained open communication and committed to "doing things differently from the way things had been done for many years" (Fairbanks, 2007, p. 80). In addition, Fairbanks indicates that support from leadership was critical to the success of the Improvement phase. The changes in the hospital's patient flow process resulted in a dramatic on-time improvement from 12 percent in December 2005, to 89 percent (Fairbanks, 2007, p. 80). This dramatic change was attributed to reducing the amount of time it takes to transport patients, administering anesthesia and other necessary medications in a timely manner, surgeon's confidence that patient will be transported on time when they are finished on time, and eliminating telephone calls and communication among team members when patients are admitted. In addition to an improvement in surgeries being completed on time, turnaround times also decreased form a mean of 23.8 minutes to 17.9 minutes (Fairbanks, 2007, p. 80).

The final phase, Control, assures that improvements are sustained. In this hospital setting, staff members were assigned specific tasks to ensure sustainability and to ensure that there was no loss of interest by stakeholders. Although Lean Six Sigma focuses on process improvement, an important outcome in this hospital project was the improvement in morale among staff members. Fairbanks states, "after Lean Six Sigma initiatives were employed, staff members noted a greater sense of cohesiveness, collaboration, and pride in their accomplishments" (Fairbanks, 2007, p. 81).

\subsection{Lean Six Sigma Applications in Dispensing Practices In her article, "Lean Six Sigma Reduces Medication Errors," Esimai (2005) illustrates the use of Lean Six Sigma methodology in a healthcare setting, specifically a pharmacy in an anonymous hospital. Similar to the previous article, Esimai (2005) walks the reader through the five phases and provides detailed} descriptions of what was done in each phase and the outcomes. The problem at this 
hospital directly relates to our study. They were experiencing an increase in the rates of error in medication administration records. A project team was assembled with an objective to conduct investigations and come up with a process that would greatly minimize medication errors. The project team consisted of individuals who were in positions to "recommend and implement interventions to error reduction" (Esimai, 2005, p. 51).

The project team began by defining the problem and, for the purpose of consistency, then determined that the most urgent problem was the unknown error rate in the hospital medication-administration records. They reviewed and verified the process maps against current practices and sequence of operations. They reviewed the errors found in the pharmacy medication order entry process (OE) and began to clearly define those errors and their origins. Subsequently, they discovered that physician comments and instructions that were indicated on original faxed orders were not being inputted by the pharmacy, medication dosages were different from the original faxed order, wrong drugs or different descriptions from the original faxed order were being processed, the frequency of the drug dosages were different from the original faxed order, certain medications were omitted without reasons, some medications were profiled twice with different prescription numbers, discontinued medications were still being entered into the pharmacy OE, faxed medications were not received or could not be located by pharmacy personnel, incorrect profiles of medications were ordered, and medications were profiled and routed incorrectly (Esimai, 2005, p. 52).

The project team found that some employees committed as many as 112 errors in a two-month period while some committed zero errors. The team reviewed the errors with employees and found that many of the errors were committed because of a "misunderstanding of certain guidelines and instructions" (Esimai, 2005, p. 53). The pharmacy conducted training and provided close supervision of its personnel to ensure that standard procedures were being adhered to. The project 
team used statistical methods to estimate the trends of the errors and created charts and graphs that depicted positive trends.

After the investigation, in the Analysis phase, the project team found that there were many contributors to the existing problem. For example, they found that there were problems with the fax machine, difficulties with understanding physician's handwriting, distractions and interruptions when entering information in the system, non-reconciliation among nurses and pharmacists regarding the route, frequency and times of day to administer medication, and oversight due to human errors attributed to stress and an unpleasant working environment.

Part of the Improvement phase involved redesigning the pharmacy's process maps and installing new equipment. The project team also recommended that the hospital institute a high-performance standard through instruction and supervision, fully implement computerized physician order management, install a system to separate the fax line from the phone lines, agree on standards of medication administration, designate one pharmacy employee to handle all external calls, and, finally, hold monthly meetings so that nurses and pharmacists could build better relationships. Esimai (2005) suggests that "in healthcare, the best approach appears to be error prevention using software that flags mistakes so employees will take immediate corrective action" (Esimai, 2005, p. 55).

The implementation of Lean Six Sigma at this hospital resulted in a decrease in both the number of order entry errors and in total error rate from $0.33 \%$ to $0.14 \%$ in five months as well as an estimated labor cost reduction of $\$ 550,000$. In addition, "improved employee morale and better relationship between nurses and pharmacists" along with patient satisfaction were also results of the success of implementing Lean Six Sigma (Esimai, 2005, p. 57).

By implementing the Lean Six Sigma approach, many organizations have realized that it is possible to streamline their operations to create value that would benefit management, employees and customers. Many companies' bottom lines 
have soared with the successful implementation of Lean Six Sigma. Organizations are drawn to the Lean Six Sigma methodology because it can be implemented and produce results rather quickly without increasing cost to the organization.

The previous articles all present Lean Six Sigma in a positive light without providing any counter-arguments and without illustrating anything that could potentially go wrong. Not surprisingly, not everyone shares the belief that Lean Six Sigma is a cure-all for cost savings and process improvement. In his article "A Values-Based Critique of Lean and Six Sigma as a Management Ideology," Paparone (2008) suggests that "organizational cultures that are attracted to the Tayloristic (scientific management) qualities of LSS-type systems may be blinded to other important interpretations of effectiveness and criteria for decision making" (2008, p. 35). Paparone does not suggest that Lean Six Sigma does not work; rather, he suggests that total reliance on Lean Six Sigma for process improvement will cause an organization to miss opportunities to learn new ways of improving their processes. 


\subsection{The Pharmacy Cost Structure}

As a background to the discussion of the cost structure of pharmacy operations, we first present a summary of congressional legislation and policies that have impacted military healthcare. This will be followed by a discussion of the cost structure of military healthcare and, specifically, the cost structure of MTF pharmacies in such areas as manpower, facilities, and pharmaceuticals.

\subsection{Congressional Legislation}

The discussion on the congressional legislation and policy is broken down into four subsections that address TRICARE for life, cost-sharing initiatives, reserve benefits and new legislation for pharmaceuticals.

\subsubsection{TRICARE for Life}

TRICARE for life (TFL) is a relatively new healthcare benefit that extends medical and prescription drug coverage to beneficiaries who would have ordinarily sought coverage under Medicare and Medicaid. Although not contractually stipulated in the enlistment contracts of service members, the traditionally held belief has been that medical and prescription coverage would be a benefit to service members and their dependants until death. In 2001, Congress enacted legislation that enveloped members and dependents under TRICARE ensuring continual coverage until death. TFL beneficiaries are able to seek medical attention at any MTF on a space available basis, but can utilize any MTF pharmacy without restriction.

\subsubsection{Cost-sharing Initiatives}

The current legislated co-pay by beneficiaries for prescription drugs is $\$ 3$ for generic medication and $\$ 9$ for brand-name medication. The DoD planned to raise co-payments of beneficiaries for pharmaceutical benefits from $\$ 3$ for generic and $\$ 9$ for brand-name drugs to $\$ 5$ and $\$ 15$, respectively (CBO, 2008). However, the 
National Defense Authorization Act of 2008 defeated that plan in favor of freezing co-payments at their current level. This freeze will remain in effect through 2009 and will cover all beneficiaries of the DoD pharmaceutical benefits. The CBO estimated that this freeze in planned co-payment amounts would increase direct spending under that program by $\$ 99$ million over the remainder of 2008 (CBO, 2007). Without adjustments to beneficiary co-payments, the TRICARE pharmacy benefit will continue to accumulate costs for the program (CBO, 2007). The pharmacy benefit to beneficiaries has significantly grown to cover baby-boomers and their dependents, a significantly expanded "active duty" reserve force, and a growing active-duty force fighting the War on Terrorism. Without a raise in co-payments, a $\$ 99$ million shortfall in the cost of support to pharmacy operations will continue to grow over the coming years.

\subsubsection{Reserve Benefits}

The US Military Reserves and the states' National Guards receive medical, dental, and pharmacy benefits during their service on active duty. Since September 11,2001 , there have been numerous reserve and guard units that have been called to active duty for service in the continental US, Afghanistan, and Iraq. Most units being activated are serving periods of at least 18 months. The service consists of six months of training prior to deployment and then a one-year deployment. After numerous incidents of deployment delays, due to medical issues with reserve and guard service members, deployment orders authorized members to start receiving benefits up to 90 days prior to their report date. This new procedure attempted to ensure that all reporting members were medically fit for duty. However, for the DoD healthcare system, this also meant a surge in the number of beneficiaries that started receiving benefits, lasting up to 22 months. With the current Global War on Terrorism, a healthcare system that is predominately sourced to provide care for active duty personnel, dependents and retirees is being stretched beyond its means. 


\subsubsection{New Legislation for Pharmaceuticals}

Under the current pricing for pharmaceutical procurement, pharmaceutical companies provide significant cost savings to the military under the Federal Supply Schedule (FSS). The military is able to provide medications through MTFs and the TRICARE Mail Order Program (TMOP) at the same reduced rates under the FSS; however, previously these reduced rates did not encompass medications procured by beneficiaries at retail pharmacies. Under the National Defense Authorization Act of 2008, section 703 now requires drug manufacturers to provide FSS pricing on purchases covered by TRICARE at all retail pharmacies. Again, this highlights the previous discussion on the identical pricing for all drugs destined for the DoD's patient consumption. The $\mathrm{CBO}$ estimates that implementing this section would reduce direct spending by $\$ 2.6$ billion over the $2008-2013$ periods (CBO, 2008). The new legislation has done a lot to address costs incurred by the Department of Defense from the use of retail pharmacies by beneficiaries but fails to address escalating costs within military pharmacies and the growing pool of beneficiaries of the pharmacy benefit.

\subsection{The Pharmacy Costs}

At present, the US military is fully engaged with commitments to the Global War on Terrorism and other Stability and Support missions across the globe. As a result of these worldwide commitments, funding within the DoD has become a critical issue and more so with the joint-service medical departments. The medical departments have to fund deployed troops as well as provide needed support for veterans and service members alike not only in forward-deployed areas but also in the United States. Regardless of the actual size of the annual Defense Authorization Act, Congress cuts the defense budget annually. The subsequent effects of these budget cuts are seen throughout the services' respective medical commands that have to operate their departments with what they believe to be a minimal amount of staff to provide the maximum amount of capacity. One such department is the pharmacy, which is located within every MTF. 
The DoD has also long operated on a "spend it all-up" culture with regard to budgeting. This defense-spending culture must be overcome, particularly when it comes to fully instituting civilian business practices, i.e., Lean Six Sigma, in the DoD in order to truly capture cost savings.

As seen in Figure 1, medical cost has grown considerably since 1980 in comparison to other funded areas. The cost of medical benefits to beneficiaries is growing to encompass more than $20 \%$ of total Operations and Support monies. This is a fact of life in the civilian healthcare arena as well as in the military. The DoD projected that growth in medical spending was expected to be nominal with the proposed increase in co-payments and user fees; however, as seen in the 2008 Defense Appropriations Bill, that effort went unsupported by Congress. Now it is more likely that medical spending will increase to $\$ 63.3$ billion, or a real expenditure increase of $65 \%$. These figures directly feed back into the analysis of the total Operations and Support (O\&S) spending for the military. Increases in medical spending in O\&S will account for 37\% of the growth in that account by 2024. (CBO, 2007).

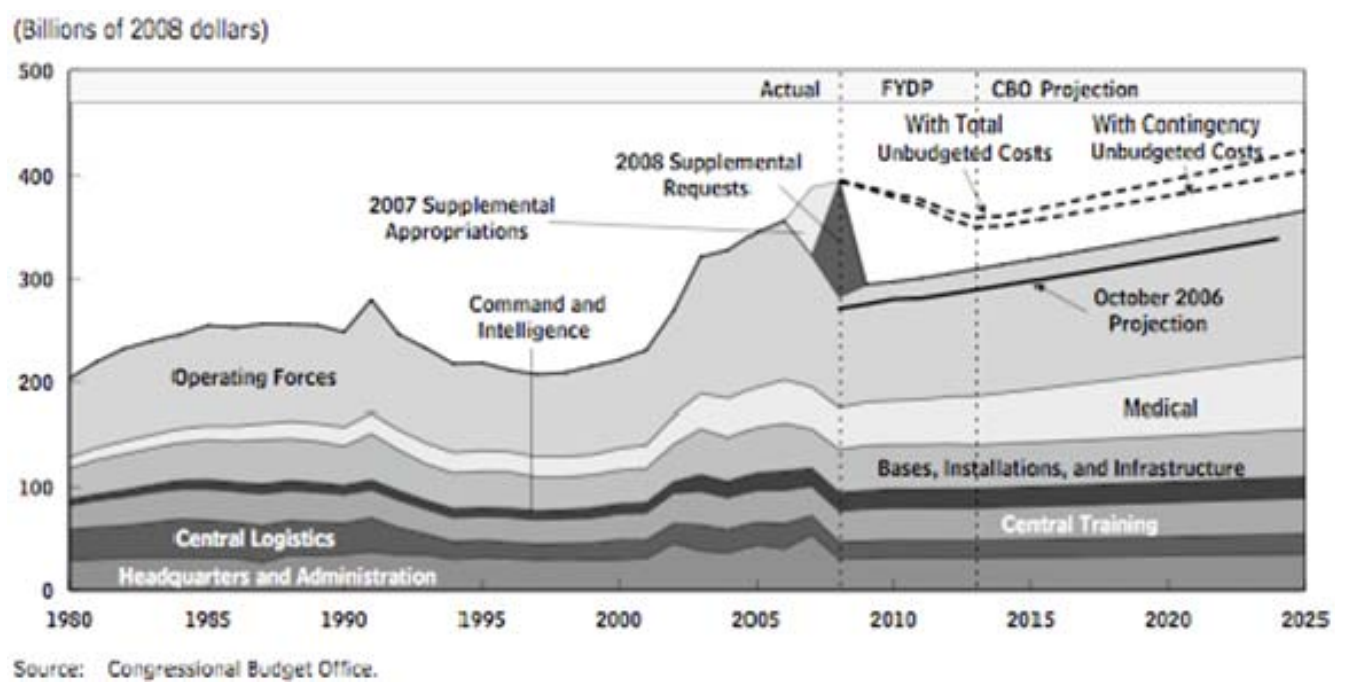

Figure 1. Growth of Medical Expenditures and Projection for the DoD 
The cost of the pharmacy is growing at a rate higher than that of the total cost of military healthcare itself. As in the civilian sector, pharmaceutical costs are growing at an alarming rate. These costs, as seen in Figure 2, for the military have "grown more than 200 percent" since 2000 and will likely continue to grow due to pharmaceutical company's R\&D costs (Henning, 2008). The $200 \%$ increase encompasses a growth in pharmaceutical funding of more than $40 \%$.

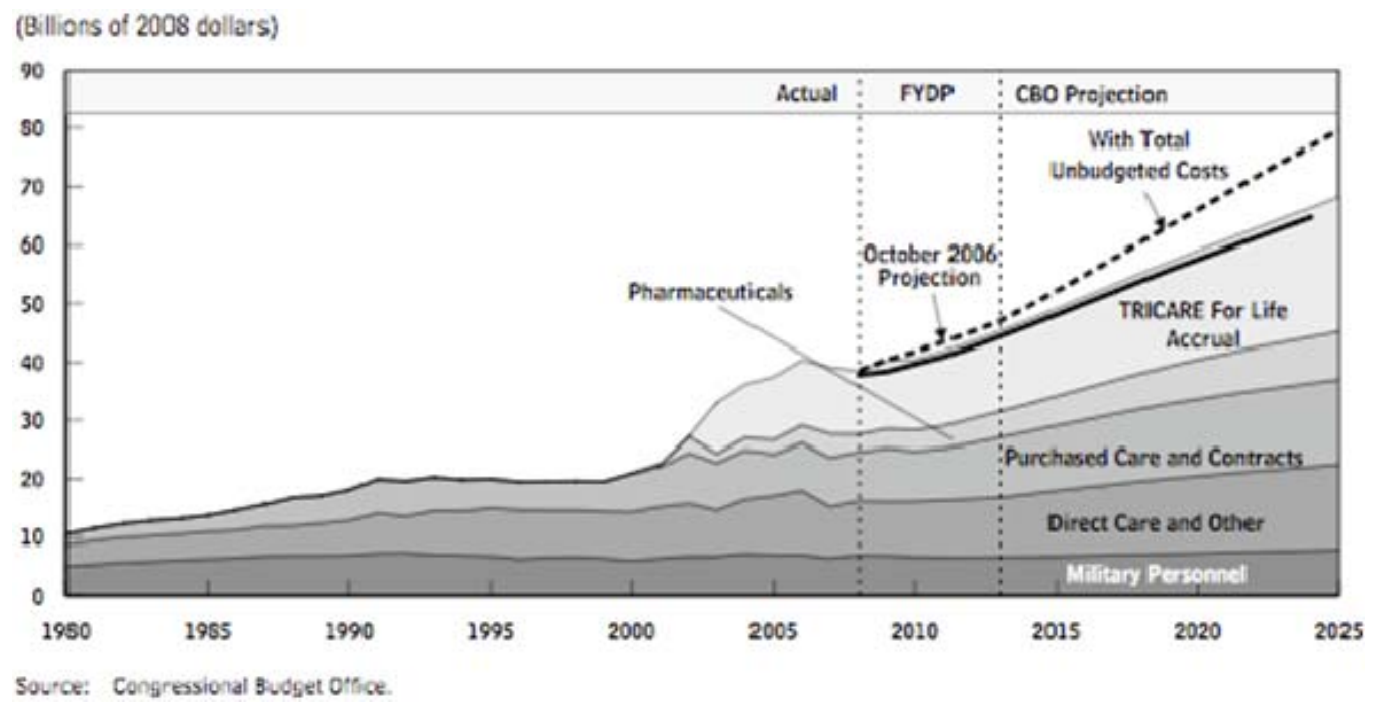

Figure 2 Past and Projected Resources for the Military Medical System

TFL essentially covers active duty from enlistment to retirement to death. TFL also must deal with the cost of continuous operations with supplements from beneficiary co-payments. With any other government-funded benefit, whether it's a bridge, expressway, or even a parking garage, there must be a payment on the part of the customer for the service. This service fee-or in the case of the pharmacy benefit, a co-payment-is augmented or even gets reduced funding based on the anticipated fee. However, Congress has increased the pool of beneficiaries without regard to properly sourcing the funding and restricted the medical department from increasing co-payments to make up for the difference. This has made and will continue to make a significant impact on TFL accruals as shown by the October 2006 projection with total unbudgeted costs in Figure 2. Based on this new congressional policy or postponement of the DoD policy regarding co-pay, CBO has 
changed their cost estimates for medical spending in the coming years. CBO now estimates a growth in medical spending to $\$ 68.3$ billion and a real increase of $77 \%$.

TFL is funded by payments from beneficiaries and put into a healthcare fund that is, in turn, charged against monies appropriated for military personnel pay. If annual accrual charges are taken into consideration for that account, CBO projects that the accrual changes for the TFL benefit will grow from $\$ 9.3$ billion to $\$ 20$ billion in the coming years (CBO, 2007). Of that growth, accrual payments for the pharmacy will account for $40 \%$. Regardless of the fact that MTF care for retirees is not a new benefit, MTF care for retirees over the age of 65 should be taken into consideration since prior to 2001 they fell under Medicare and Medicaid and would not have normally been seen at MTFs.

Now that costs involving congressional legislation, TFL, reserve benefits and cost-sharing initiatives have been discussed; manpower, facilities, and dispensing will be outlined to demonstrate their impact on the cost of pharmacy operations.

\subsubsection{Manpower Costs}

The past and continuing trend in the military, and especially in the medical department, has been to utilize civilian manpower in lieu of military. A review of the most recent military and government service employee pay-charts for 2008 yields interesting information. The DoD is outsourcing its manpower to civilians at a cost higher than it would already pay its military service members. If it is taken into consideration that troop strengths within the services are quite steady and actually have grown in the years since 9/11, then these manpower costs would have to be considered as sunk costs. Table 1 depicts the average yearly salary for a pharmacy technician and a pharmacist under 2008 pay-charts.

\begin{tabular}{|l|l|l|l|l|r|}
\hline Worker & Pharmacy Tech & Pay & Pharmacist & Pay & Total \\
\hline Civilain & GS4 & $\$ 25,824$ & GS10-12 & $\$ 58,210$ & $\$ 84,034$ \\
\hline Military & E1-4 & $\$ 20,358$ & CPT/LT & $\$ 54,540$ & $\$ 74,898$ \\
\hline
\end{tabular}

Table 1 Pay Comparison for GS and Military Pharmacy Employees 
A typical civilian pharmacy technician starts at a GS 4 , making $\$ 25,824$ a year and ranges up in grade while their military counterpart ranges in rank from E1-E4, averaging less at $\$ 20,358$ a year. For DoD civilian pharmacists' with pay grades GS $10-12$, the average salary is $\$ 58,210$, while the military pharmacists are annually paid $\$ 54,540$. A simple comparison of salary figures suggests that civilian employees cost more to DoD than military. However, if employee benefits are included the comparison is more complicated. Military benefits seem to cost more to DoD than the civilian employee benefits. Pharmacy officers receive special pay. On the other hand Civilian employees tend to stay in the job for a longer period which reduces retraining cost. Many military hospital pharmacies hire pharmacists or pharmacy technicians as contractors instead of GS employees to reduce overhead. Estimation of true savings via the cost befit analysis of the total manpower cost is important, yet it is the focus of this research.

\subsubsection{Dispensing Costs}

This section will cover the three methods in which beneficiaries of the DoD pharmacies are able to obtain their medical prescriptions: through local civilian pharmacies, through the TRICARE Mail Order Program (TMOP), and through the local MTF pharmacy.

All three methods have their benefits to the patient; however, until the National Defense Authorization Act of 2008 there were different individual drug costs associated to all three programs, to the customer, and to the DoD. Before this act, the cost of obtaining medications through local civilian pharmacies did not fall under the Federal Supply System (FSS), and items such as aspirin varied in price between the MTF, civilian pharmacy, and TMOP. The costs that beneficiaries would see for utilizing local civilian pharmacies were $\$ 3$ for generic drugs and $\$ 9$ for brand-name drugs for up to a 30-day supply. The same copayments would apply to the TMOP for up to a 90-day supply, No copayments applied at the MTFs. However, since those medications were not covered under the FSS agreement, the DoD would see significantly higher bills for their portion of the beneficiary visit to the pharmacy due 
to the procurement costs of drugs. As of 2008 , the DoD pays the same for all three beneficiary procurement choices. However the change does not affect copayments charged to the : \$3 for generic and $\$ 9$ for brand-name medications for a 30-day supply at a local pharmacy, or for a 90-day supply at TMOP, and no copayments at the MTFs.

Now that dispensing costs for all three beneficiary procurement choices are the same for the DoD and under the FSS agreement, there is not much of a benefit for further discussion on how to save money for the DoD, invalidating the previous work on least-cost procurement methods studied by Henning (2008), for example. Other studies have looked at the savings of time and money that can be reaped by the beneficiary associated with their procurement method: MTF, civilian pharmacy, and TMOP. Since the same copayment covers three times more medications at the TMOP than at retail pharmacies, and no copayments at the MTFs, there is much to be considered for beneficiaries with the cost of fuel, time in line and overall convenience; however, this is not within the scope of our study.

What is within the scope of our study, however, is how to save money and increase efficiency through implementing Lean Six Sigma methodology in the MTF pharmacy. Pharmacy business operations and methodology will be discussed in the following chapter, but improvements in the cost of operations are directly impacted by the beneficiary's choice in medication procurement options. Refill medications take up approximately $15 \%$ of the MTF pharmacy's time. The refills can be more effectively and economically serviced by a mail-order pharmacy. The less time the MTF pharmacy spends on filling refill prescriptions, the more time personnel can spend on filling inpatient and outpatient prescriptions (Kelly, 2008). Freeing up the time of the MTF pharmacy from doing refills could improve efficiency on the aforementioned prescriptions and enable possible reductions in manpower, facilities and the volume of medications in the pharmacy. 


\subsection{Improving Pharmacy Operations with Lean Six Sigma Tools}

With the main goal of improving the performance of pharmacy operations at Travis AFB, the study started with the application of various tools and techniques prescribed in the DMAIC methodology (Define, Measure, Analyze, Improve and Control) of Lean Six Sigma.

To better understand the nature of pharmacy operations and the challenges and opportunities encountered in applying LSS tools and techniques to improve the pharmacy operations, we selected three military pharmacy locations that were

geographically close and diverse in terms of size and branch of service. Specifically, we selected the Army's Defense Language Institute (DLI) in Monterey, CA; Travis Air Force Base in Fairfield, CA; and the San Diego Naval Base in San Diego, CA. After identifying the facility locations, the necessary approvals for undertaking these studies were obtained. Subsequently, the study team visited all three facilities to observe the operations in person, conduct interviews of the pharmacy personnel and customers, and collect the necessary data.

In our study, we found that although the specific issues differed from one facility to the next, the core operational and business processes used at all three facilities were fairly similar. Hence, for the purpose of brevity, we will illustrate the application of LSS tools and techniques in the next three sub-sections of this chapter by describing their use at Travis AFB. The details of the studies at other two locations can be found in Nuce, Robinson \& Sikora (2008). The summarized results of those studies are presented in the fourth and fifth sub-sections of this chapter.

\subsection{Travis AFB Pharmacies: An Overview}

The pharmacy operation at Travis AFB consists of three separate pharmacies: the main hospital pharmacy that services Provider Order Entry (POE) patients (who have seen healthcare providers at the military facility), the Post 
Exchange (PX) annex pharmacy that services script patients (who have seen civilian healthcare providers and brought manual prescriptions), and the call-in refill pharmacy that services refills. The hospital maintains more than 600 line items of inventory and spends an average of $\$ 2.2$ million a month on medications. The separation of the pharmacy operations in three locations was undertaken to improve the operational focus for improved efficiency and reduced patient processing time. Each pharmacy is completely separate in terms of the pharmacy personnel and physical stock of pharmaceuticals inventory that supplies medicines for daily operations. The hospital's Medical Logistics personnel restock each pharmacy individually.

The main hospital pharmacy at Travis was the second-largest facility included in our study and was chosen as a representative of all medium-sized hospitals in the military. The hospital currently employs 15 military pharmacy technicians, seven contractor technicians, one civilian (GS) technician and one civilian (GS) pharmacist. The facility processes an average of 960 drug orders per day, or about 21,100 orders per month. The 24 total employees process an average of 40 orders per day per employee. The personnel cost of the pharmacy is about $\$ 62,700$ per month, with a total of 21,100 scripts processed. Thus, the labor cost of processing each script, without considering other overhead costs, is $\$ 2.97$ per order. (See Table 2)

\begin{tabular}{|l|c|c|}
\hline & $\begin{array}{c}\# \text { of } \\
\text { employees }\end{array}$ & Cost/yr \\
\hline Pharmacist (GS10-12) & 1 & $\$ 63,200$ \\
\hline $\begin{array}{l}\text { GS Pharmacy Technician } \\
\text { (GS 4-7) }\end{array}$ & 1 & $\$ 32,398$ \\
\hline $\begin{array}{l}\text { Civilian Pharmacy } \\
\text { Technician (contractors) }\end{array}$ & 7 & $\$ 272,139$ \\
\hline $\begin{array}{l}\text { Military Pharmacy } \\
\text { Technician (E2-E6) }\end{array}$ & 15 & $\$ 279,036$ \\
\hline \multicolumn{1}{|c|}{ Total } & 24 & $\$ 752,253$ \\
\hline
\end{tabular}

Table 2. Travis AFB Main Pharmacy-Employee Annual Pay Table (FY08) 
The annex employs two military pharmacy technicians, two contractor technicians, one GS technician and one GS pharmacist. The annex maintains more than 340 line items of inventory. The facility processes an average of 281 drug orders per day, or 7,033 per month. Each of the six employees processes an average of 47 orders each day. The personnel cost of the six employees totals $\$ 21,731$ per month (or $\$ 226,776 / y r$ ), with 7,033 scripts processed. The labor cost of processing each script without considering overhead is at $\$ 3.08$ per order; the unit labor cost is about the same as in the main pharmacy (see Table 3).

\begin{tabular}{|l|c|c|}
\hline & $\begin{array}{c}\text { \# of } \\
\text { employees }\end{array}$ & Cost/yr \\
\hline Pharmacist (GS10-12) & 1 & $\$ 63,200$ \\
\hline $\begin{array}{l}\text { GS Pharmacy Technician } \\
\text { (GS 4) }\end{array}$ & 1 & $\$ 32,398$ \\
\hline $\begin{array}{l}\text { Civilian Pharmacy } \\
\text { Technician (contractors) }\end{array}$ & 2 & $\$ 77,754$ \\
\hline $\begin{array}{l}\text { Military Pharmacy } \\
\text { Technician (E2-E6) }\end{array}$ & 2 & $\$ 53,424$ \\
\hline \multicolumn{1}{|c|}{ Total } & 6 & $\$ 226,776$ \\
\hline
\end{tabular}

Table 3. Travis AFB Annex-Employee Annual Pay Table

The refill pharmacy is designed to service only refill patients that have been set up in the refill tele-order system. The pharmacy is co-located at the Post Exchange shopping annex with the annex pharmacy.

The Travis Refill Pharmacy was not modeled as part of the analysis. The refill pharmacy has no variation in its process since it services only refills. The refill facility employs six technicians and processes over 1,200 scripts a day. This averages 200 scripts per technician and is the best script-processing ratio of any area studied. The unit labor cost excluding overhead is estimated to be $\$ 0.69 /$ script. Compared to the main pharmacy at $\$ 2.97 /$ script or annex pharmacies at $\$ 3.06$, the refill pharmacy is highly efficient in terms of the labor cost (see Table 4). 


\begin{tabular}{|l|c|c|}
\hline & $\begin{array}{c}\text { \# of } \\
\text { employees }\end{array}$ & Cost/yr \\
\hline $\begin{array}{c}\text { Pharmacist (GS10- } \\
\text { 12) }\end{array}$ & 1 & $\$ 63,200$ \\
\hline $\begin{array}{l}\text { GS Pharmacy } \\
\text { Technician (GS 4) }\end{array}$ & 1 & $\$ 30,639$ \\
\hline $\begin{array}{l}\text { Civilian Pharmacy } \\
\text { Technician } \\
\text { (contractors) }\end{array}$ & 2 & $\$ 77,754$ \\
\hline $\begin{array}{l}\text { Military Pharmacy } \\
\text { Technician (E2-E6) }\end{array}$ & 2 & $\$ 53,424$ \\
\hline \multicolumn{1}{|c|}{ Total } & 6 & $\$ 225,017$ \\
\hline
\end{tabular}

Table 4. Travis AFB Refill Pharmacy—Personnel Pay Chart

\subsection{Application of Selected LSS Tools}

As mentioned earlier, the DMAIC methodology consists of five phases-

Define, Measure, Analyze, Improve and Control—and each of the phases involves the application of several standard tools of techniques. We describe below the application of four selected LSS tools that were found to be particularly useful: SIPOC chart, Voice of Customer (VOC), Process Flow chart, and Fishbone (Cause and Effect) diagram.

\subsubsection{SIPOC}

The purpose of the SIPOC (Suppliers-Inputs-Process-Process-OutputsCustomers) chart is to obtain a high-level, comprehensive view of the critical entities and elements of the process under study. The development of a SIPOC chart will help the project team and sponsor agree on the boundary and the scope of the project. Equally important, it will also help the project team identify and focus on the critical aspects of the process under study. 
The SIPOC chart for the pharmacy operations is provided in Figure 3 below. The critical suppliers of drugs for these pharmacies are either the pharmaceutical prime vendor, Cardinal Healthcare, or an alternate source of supply-throughprocurement with the pharmacy's government purchase card. Patients should also be seen as suppliers of each pharmacy since they bring in the medication orders. The inputs are the orders processed in the system and the actual pharmaceuticals and drug handled in the process. The process consists of receiving the orders, processing them as necessary for distribution, and, finally, delivering the filled orders to the patients. The outputs are the patient receiving the filled order and the governmental expenses incurred in both the inputs and the process. Finally, the customers include the patient and the DoD.

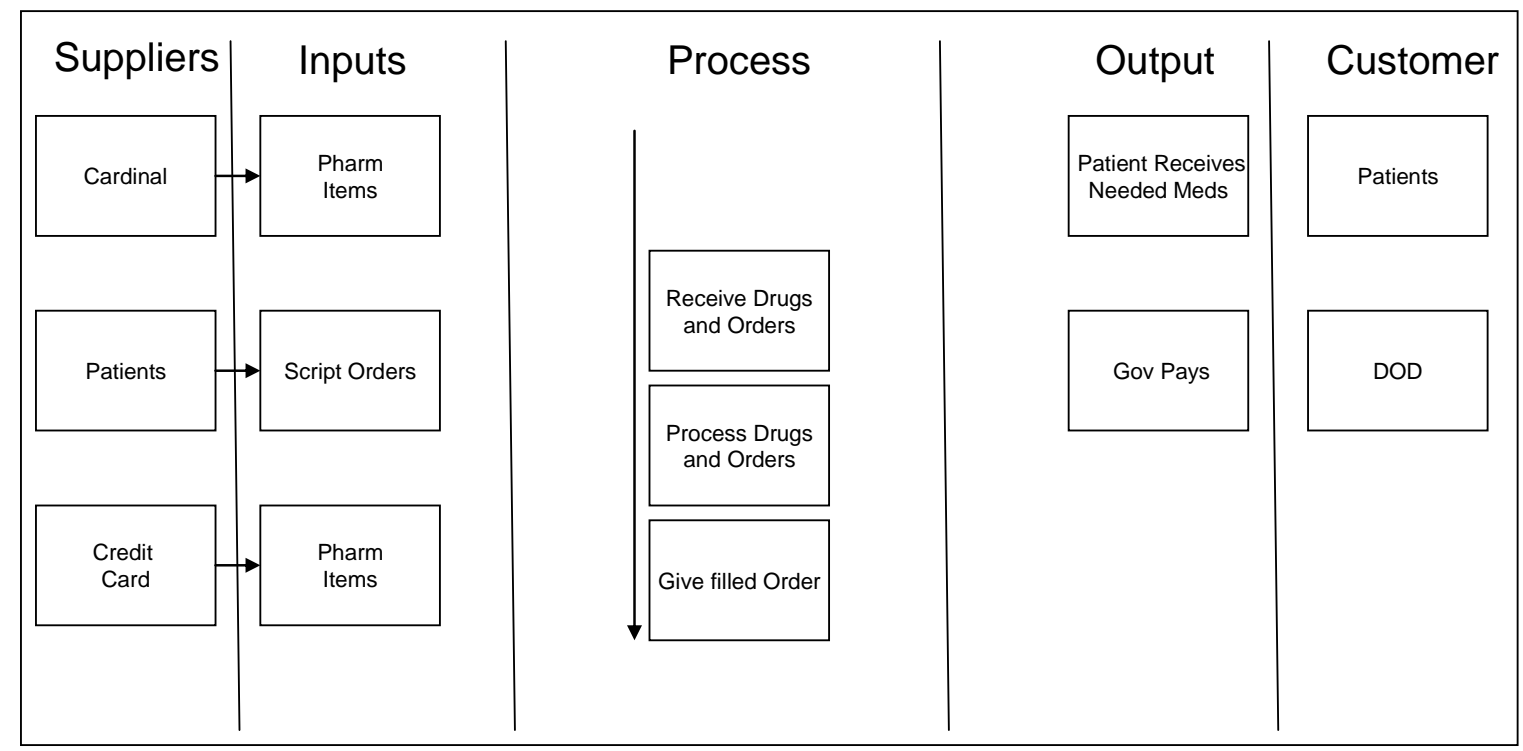

Figure 3. SIPOC Chart

Identifying the critical customers and defining the problem(s) as indicated by the customers are typically the first steps in the LSS process. The problem for the Department of Defense, as previously discussed, is the rising costs of healthcare and pharmaceuticals coupled with the budget cuts and the constraints that leave the DoD questioning how much to cut and from where. The researchers believe that significant savings can be generated through increases in efficiency and better use 
of manpower, thus cushioning the quality of delivered pharmacy services from the budget cuts and cost increases.

There are several facets within the scope of this study regarding the identification of critical customers. First, the pharmacy customers who will be receiving prescriptions must be considered because as end-users, they will ultimately be affected by the changes to pharmacy operations. Our hope is that any proposed changes will positively impact the quality of care and service that users of MTF pharmacies receive. It is important to note that patients are not the only customers of MTF pharmacies. Doctors and nurses requiring pharmaceuticals for emergent-care patients are also indirect customers of MTF pharmacies. Personnel working within the pharmacy, i.e., pharmacists, pharmacy technicians, etc., are also indirect customers. While pharmacy personnel may not use the pharmacy, they will observe the effects of LSS and may be responsible for changes to current pharmacy operations. Commonly seen effects of LSS such as increased efficiency, decreased workload and decreased manpower utilization will ultimately benefit all pharmacy employees. However, for the purposes of this study, these users are not primary beneficiaries of the military healthcare system and are not considered as critical customers.

\subsubsection{Voice of Customers (VOC)}

Satisfying the customer is critical to the success of any business process. Hence, focusing on the customer's needs is considered as the driving principle of the LSS methodology. The Voice of Customer (VOC) tool is designed to understand what the customer wants so that the process output and goals can be set to be consistent with what the customer truly needs and cares about. The current process can then be improved accordingly.

As identified earlier in the SIPOC chart, the DoD is one of the critical customers of the process. For the DoD, the goals related to the pharmacy operations are fairly clear-reducing the cost and improving the customer 
satisfaction. For the patients, however, the needs are not as clearly known. In order to better understand the problem(s) faced by the patient, the research team decided to ask patients directly by having them complete a survey. The survey covered questions about patient demographics, travel time to the pharmacy, wait-time information, and overall satisfaction with pharmacy services.

Our research team conducted a survey of patients at each pharmacy in order to gauge the overall effectiveness and quality of service of the respective pharmacy. We also attempted to measure patient satisfaction and their receptiveness to changes within the current processes, which may impact patients. Measurements such as the convenience of the pharmacy location and the reasons for utilizing one pharmacy over another may also indicate satisfaction and cost impact of one particular pharmacy over another.

The sample population was taken from all outpatients utilizing each pharmacy on the days visited by the research team. Race, ethnicity and gender played no role in the population selection and were not recorded. Surveys were conducted face-toface at the pharmacy locations themselves. Inpatients and medical personnel utilizing pharmacy services did not participate in the survey. The survey was conducted during peak hours (from 0800 to 1200 hours) and 100\% of pharmacy customers who entered the waiting area during that time were asked to participate. A small number (three) were incapable of participating due to health conditions or handicap. Seventeen percent of the patients contacted chose not to participate in the survey while the remaining (i.e., 83\%) of the patients visiting the pharmacy participated in the survey. The survey conducted at the Travis main pharmacy resulted in the participation of 38 patients, as seen below in Table 5. 


\begin{tabular}{|c|c|c|c|}
\hline \multicolumn{2}{|c|}{ Service Component } & \multirow[b]{2}{*}{ AF } & \multirow[b]{2}{*}{ CG } \\
\hline Army & Navy & & \\
\hline $6.67 \%$ & $26.67 \%$ & $60.00 \%$ & $6.67 \%$ \\
\hline \multicolumn{4}{|l|}{ Status } \\
\hline A/D & Retired & Dependent & \\
\hline $6.67 \%$ & $66.67 \%$ & $26.67 \%$ & \\
\hline \multicolumn{4}{|l|}{ Frequency of Visit } \\
\hline Less than monthly & Greater than monthly & Monthly & \\
\hline $40.00 \%$ & $33.33 \%$ & $26.67 \%$ & \\
\hline \multicolumn{4}{|l|}{ Distance } \\
\hline$<20$ miles & 20-50 miles & $>50$ miles & \\
\hline $46.67 \%$ & $33.33 \%$ & $20.00 \%$ & \\
\hline \multicolumn{4}{|l|}{ Mode } \\
\hline Self-transport & Other & & \\
\hline $100.00 \%$ & $0.00 \%$ & & \\
\hline \multicolumn{4}{|c|}{ Favorability of home delivery } \\
\hline Favorable & no opinion & & \\
\hline $80.00 \%$ & $20.00 \%$ & & \\
\hline \multicolumn{4}{|l|}{ Average Wait time } \\
\hline$<30$ minutes & $30 \mathrm{~min}$ to $1 \mathrm{hr}$ & $<1 \mathrm{hr}$ & \\
\hline $33.33 \%$ & $53.33 \%$ & $13.33 \%$ & \\
\hline \multicolumn{4}{|c|}{ level of statsfaction } \\
\hline Very Satisfied & Moderately Satisfied & No opinion & \\
\hline $66.67 \%$ & $26.67 \%$ & $6.67 \%$ & \\
\hline
\end{tabular}

\section{Table 5. Travis AFB Main Pharmacy Patient Survey}

The second survey conducted was at the Travis AFB annex pharmacy and resulted in the participation of only 15 patients, as seen below in Table 6. It was conducted from 1300 to 1500 hours, and $100 \%$ of pharmacy customers who sat in the waiting area were asked to participate. Many chose not to participate due to pending appointments or a need to use other facilities on the base. Another reason for the low number of participants was that the adjacent "call-in" pharmacy for refills had an almost zero wait time since the patients came to pick up the pre-ordered medicines. 


\begin{tabular}{|c|c|c|c|c|}
\hline \multirow{2}{*}{\begin{tabular}{|l|} 
Service Component \\
Army \\
\end{tabular}} & \multirow[b]{2}{*}{ Navy } & \multirow[b]{2}{*}{ AF } & \multirow[b]{2}{*}{ Marine } & \multirow[b]{2}{*}{ Other } \\
\hline & & & & \\
\hline $7.89 \%$ & $13.16 \%$ & $71.05 \%$ & $5.26 \%$ & $2.63 \%$ \\
\hline \multicolumn{5}{|l|}{ Status } \\
\hline A/D & Retired & Dependent & & \\
\hline $36.84 \%$ & $42.11 \%$ & $21.05 \%$ & & \\
\hline \multicolumn{5}{|l|}{ Frequency of Visit } \\
\hline Less than Monthly & Greater than Monthly & Monthly & & \\
\hline $52.63 \%$ & $15.79 \%$ & $31.58 \%$ & & \\
\hline \multicolumn{5}{|l|}{ Distance } \\
\hline$<20$ miles & $20-50$ miles & $>50$ miles & & \\
\hline $81.58 \%$ & $7.89 \%$ & $10.53 \%$ & & \\
\hline \multicolumn{5}{|l|}{ Mode } \\
\hline Self-transport & Other & & & \\
\hline $92.11 \%$ & $7.89 \%$ & & & \\
\hline \multicolumn{5}{|l|}{ Favorability of Home Delivery } \\
\hline Favorable & \begin{tabular}{|l} 
No Opinion \\
\end{tabular} & & & \\
\hline $92.11 \%$ & $34.21 \%$ & & & \\
\hline \multicolumn{5}{|l|}{ Average Wait Time } \\
\hline$<30$ minutes & $30 \mathrm{~min}$ to $1 \mathrm{hr}$ & $>1 \mathrm{hr}$ & & \\
\hline $65.79 \%$ & $31.58 \%$ & $2.63 \%$ & & \\
\hline \multicolumn{5}{|l|}{ Level of Satisfaction } \\
\hline Very Satisfied & Moderately Satisfied & No Opinion & & \\
\hline $78.95 \%$ & $18.42 \%$ & $2.63 \%$ & & \\
\hline
\end{tabular}

Table 6. Travis AFB Annex Pharmacy Patient Survey

In addition to the numerical data collected in the survey, we also analyzed the data collected in the "comments" section of the survey. While numerous patients cited a significant decrease in patient processing times at the Travis AFB hospital, a relatively large number of participants (approximately 20\%) expressed an inability to confidently or accurately manipulate the pharmacy's automated systems. Customers of the Travis annex pharmacy can submit refill prescriptions via automated telephone, fax, or the Internet. However, a majority of customers surveyed were retirees and elderly and were seemingly technologically intimidated by these systems. The automated system is only utilized in the refill pharmacy. In addition, it is important to note that as the percentage of retired personnel increases, so does the average distance traveled to use pharmacy services, increasing the need for reliance on the existing automated systems in the refill pharmacy. 


\subsubsection{Process Flow Chart}

The purpose of a Process Flow chart (alternatively termed as Process Flow map or, simply, Process map) is to clearly show the sequence of steps carried out in the process, including the inputs used and outputs generated at each step. It is also useful to include information related to the resource(s) used and the waiting time and processing time needed at each step. Proving the maxim "a picture is worth a thousand words," a Process Flow chart is an excellent communication tool for describing a process.

As discussed earlier, the pharmacy operation at Travis AFB consists of three separate pharmacies: the main hospital pharmacy, the Post Exchange annex pharmacy, and the call-in refill pharmacy. The study found that the processes being carried out at three separate pharmacies were mostly similar with only minor variations concerning some details. Consequently, we present in this paper the Process Flow chart of the main hospital pharmacy as a representative sample. Flow charts of the other pharmacies can be found in Nuce et al. (2008).

The Process Flow chart of the main hospital pharmacy is depicted below in Figure 4. At a high level, the process consists of three stages: order receiving, order filling, and delivery. The sequence of detailed steps involved in the process is shown in the Process Flow chart in Figure 4. 


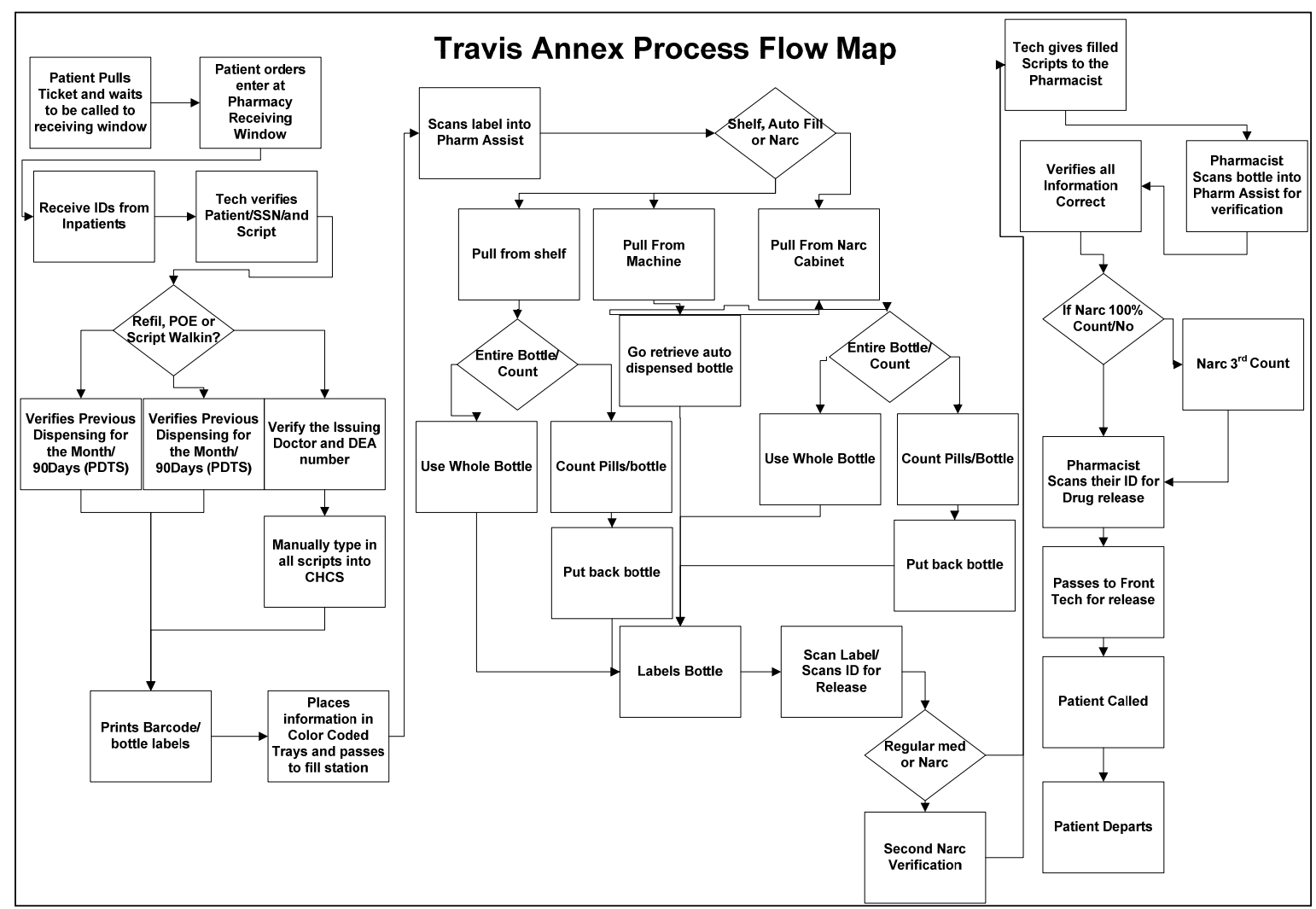

Figure 4. Travis AFB Main Pharmacy Process Flow chart

As noted in the above Process Flow chart, the pharmacy places tight restrictions on narcotic pharmaceutical and "high risk" medications, presumably due to the significantly larger employee population. The process as it is depicted above provides adequate services for the size of the pharmacy operation and the population it serves. The patient waiting in line to get to the window has no value added to the customer; but it is mitigated somewhat by an automated ticket dispenser that separates active-duty, in uniform patients from all other patients. Each patient pulls a number and waits in the waiting room until his or her number is called. The time from the moment a number is pulled to the moment the patient is called to the receiving window ranges from 30 seconds to 1.5 minutes, depending on the amount of people waiting and whether the patient is in uniform. Patients in uniform receive head-of-the-line privileges. 
The total processing time for patients ranges from 13 minutes to 28 minutes, with a mean of 18.5 minutes given the current operational configuration. The wait adds no value to the customer and this non-value added processing time could be potentially reduced if the main hospital pharmacy did not take script walk-ins and refills and instead referred those patients to the pharmacy that processes walk-in scripts and refills. During the researchers' visit to Travis AFB, congestion in the order filling operation was observed at the two fill stations within the pharmacy. When the prescription orders are passed back in the process line from the two receiving windows, they are funneled to two fill stations that are located one behind the other. Time was wasted in determining which order to process at which station. The problem was minimal when the order rate was low, but when the rate increased, the first station usually backed up.

\subsubsection{The Fishbone (Cause and Effect) Diagram}

The purpose of a Fishbone diagram (also called a Cause and Effect diagram) is to uncover the root cause(s) of the problems facing the customers. Identifying the root causes of the problem is particularly important and useful since eliminating root causes can generally lead to solving the problem. To develop the Fishbone diagram, one begins with a simple question: What are the major causes of the problem being analyzed? This is then followed with a similar question posed for each major cause identified earlier: What is the next level of cause that has led to the major cause? This process of cause-and-effect analysis is repeated several times until the root causes of the problem are identified. The entire hierarchical analysis is finally captured and represented in the form of a Fishbone diagram.

We analyzed the two major issue faced by the DoD: excessive costs in pharmacy operation and the need to improve customer service. Based on the Voice of Customer (VOC), we decided to use shorter order-processing time as an indicator of better customer service. Figure 5 below shows the Fishbone diagram for the first problem of excessive costs, while Figure 6 shows the Fishbone diagram for the second problem of excessive customer-order processing time. 


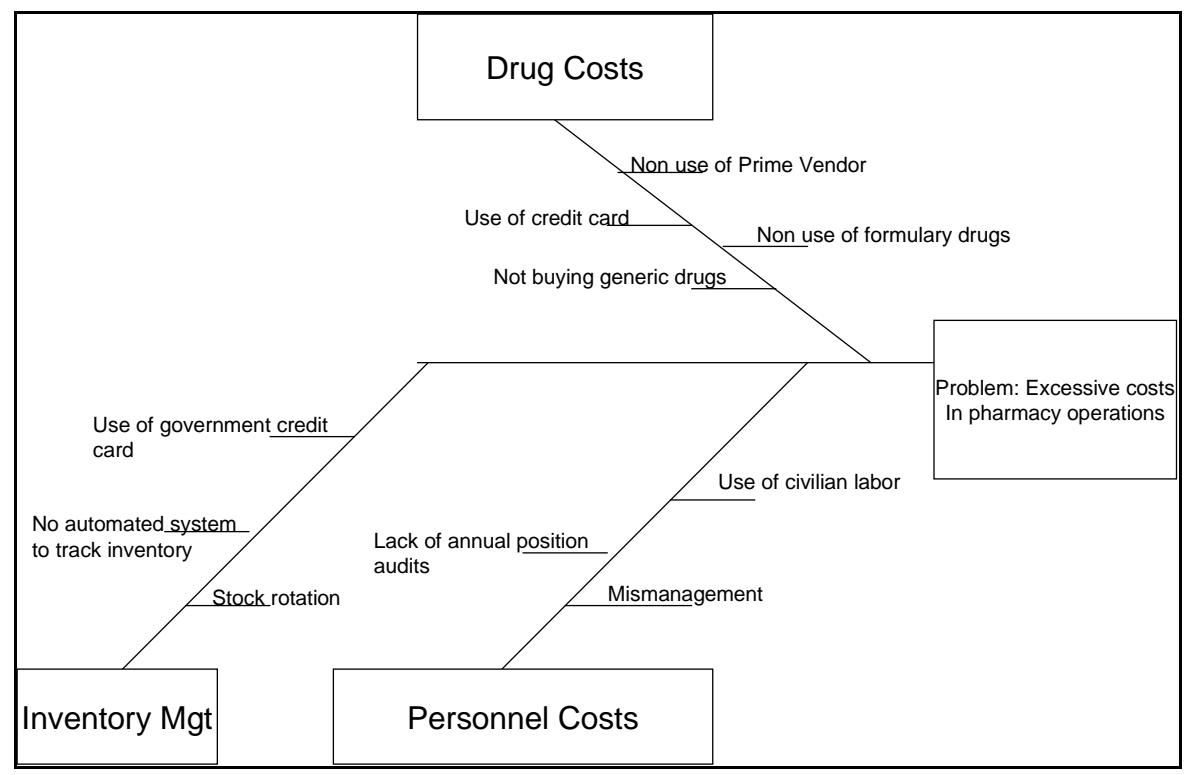

Figure 5. Fishbone Diagram for Excessive Costs

The problem of excessive costs in pharmacy operations is studied in Figure 5. The costs can be attributed to drug costs, personnel costs, and a lack of inventory management. The drug costs can come from the lack of using the contracted pharmaceutical prime vendor. Not utilizing the prime vendor negates the benefit of having a contractually agreed low price on pharmaceuticals. Any purchase of drugs from a third-party source or on the government credit card will incur higher procurement costs. Personnel costs are also an issue. Most of the pharmacies visited utilized contract employees or GS employees where military personnel could have been utilized. A personnel audit of each job position should be performed annually to justify employees. Inventory management is also a major driver of cost. Not performing stock rotation or utilizing first-in-first-out (FIFO) for stocked medications leads to expired drugs. Not having an automated inventorymanagement system leads to excess medications on hand. Moreover, with a prime vendor that resupplies daily, there should be minimal lines stocked for daily use.

The problem of excessive order processing time is analyzed in Figure 6. The increased processing time comes from the validation processing that the receiving technician must perform as each new script arrives. The processing includes 
validation of the doctor and the doctor's narcotics license (DEA number), the order, and that the medication is in fact stocked and on the formulary. Employee attitudes and legislation enforcing cost-cutting measures are other important factors. The attitudes of the employees toward their old habits and processes also indicate some resistance to change or to new ways of doing things. The regulations of a government bureaucracy can also pose certain issues, and the military finance system does not actually reward services and departments for cutting costs. A dollar saved this year is a dollar not received next year. There are also legislative measures that require cost-saving procedures in the military; however, the cost of pharmaceuticals continues to rise and budgets continue to dwindle, possibly offsetting potential gains from cost savings.

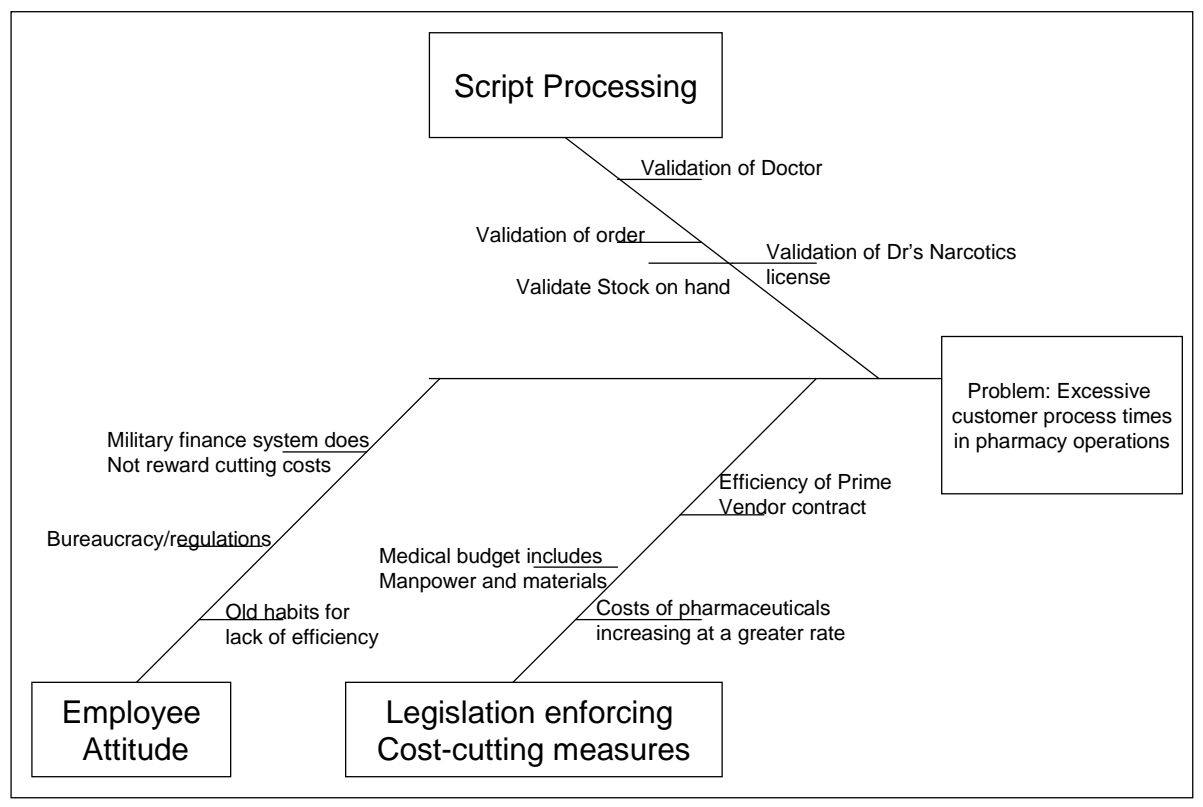

Figure 6. Fishbone Diagram for Excessive Processing Time

\subsection{Process Improvement at Travis AFB Pharmacies}

In this section, we discuss the problems identified in the previous section using LSS tools. Then, we analyze the problems and give suggestions for improving the processes or reducing patient processing time. These suggestions, as mentioned before, can be generalized and applicable to many military pharmacies. 


\subsubsection{Travis AFB Pharmacies}

The main pharmacy at Travis AFB is designed to service only the POE patients seen at the MTF. However, as shown in Table 7, the pharmacy is not only servicing its POE patients but also script and refill patients. The table depicts that approximately $1 \%$ of the patients seen are ones that should be seen at the annex pharmacy, and $5 \%$ of the patients should have used the refill pharmacy. The script and refill patients add to the overall processing time of all patients by increasing the additional workload and variability in the designed work-process flow of the main pharmacy. The increased processing time comes from the validation processing that the receiving technician must perform as each new script arrives.

The processing includes validation of the doctor and the doctor's narcotics license (DEA number), the order, and that the medication is in fact stocked and on the formulary. The process is also significantly inhibited by the patient data transaction system (PTDS) verification, new refill requests, and the manual input of all script requests. Both the new scripts and refills are first verified in CHCS for patient eligibility in order to receive services.

The orders from two receiving windows then go to a single station that processes new refill and script requests. They have to be first verified in PDTS to ensure that there was no prior dispensing within the past 90 days, after which the order must be typed into CHCS for every medication requested. The station process time could potentially be shortened if an additional station were added, thus decreasing the overall process time by increasing capacity.

As shown in Figure 7, the average processing time at the main pharmacy is significantly more than the pharmacy's target of 15 minutes most of the time. The total processing time for patients ranges from 13 minutes to 28 minutes with a mean of 19.5 minutes given the current operational configuration. However, based on a simulation study done by Nuce et al. (2008), the processing time could be potentially reduced by 7 minutes if the main hospital pharmacy did not take script walk-ins and refill orders and referred patients to the pharmacy that process refills and walk-in 
scripts. Table 7 depicts more than $5 \%$ reduction in volume if the pharmacy enforces their existing policy of filling refill scripts at the refill pharmacy.

Nuce, Robinson, \& Sikora (2008) also suggest the main pharmacy can potentially reduce the number of personnel while maintaining the same level of customer service. However, for a more concrete recommendation, more data on customer arrival times needs to be collected to fit to the right distribution. The patient processing time is very sensitive to the variability of the patient arrival pattern (or distribution of the inter-arrival times).

\begin{tabular}{|c|c|c|c|c|}
\hline Month & Script Walk-i币Provider Entry & Refill Walk-in & Total \\
\hline October & 228 & 20610 & 1174 & 22012 \\
\hline November & 130 & 18033 & 1170 & 19333 \\
\hline December & 206 & 17294 & 1077 & 18577 \\
\hline January & 277 & 21602 & 1112 & 22991 \\
\hline February & 208 & 21565 & 1002 & 22775 \\
\hline March & 144 & 21381 & 824 & 22349 \\
\hline April & 186 & 23126 & 1072 & 24384 \\
\hline May & 97 & 20612 & 1057 & 21766 \\
\hline June & 248 & 18161 & 1002 & 19411 \\
\hline July & 211 & 17326 & 1076 & 18613 \\
\hline August & 187 & 19715 & 975 & 20876 \\
\hline September & 185 & 19668 & 960 & 20813 \\
\hline Total & 2307 & 239093 & 12501 & 253901 \\
\hline Avg/Month & 192 & 19924 & 1042 & 21158 \\
\hline
\end{tabular}

Table 7. Travis AFB Main Pharmacy Patient Volume Report (FY08) 


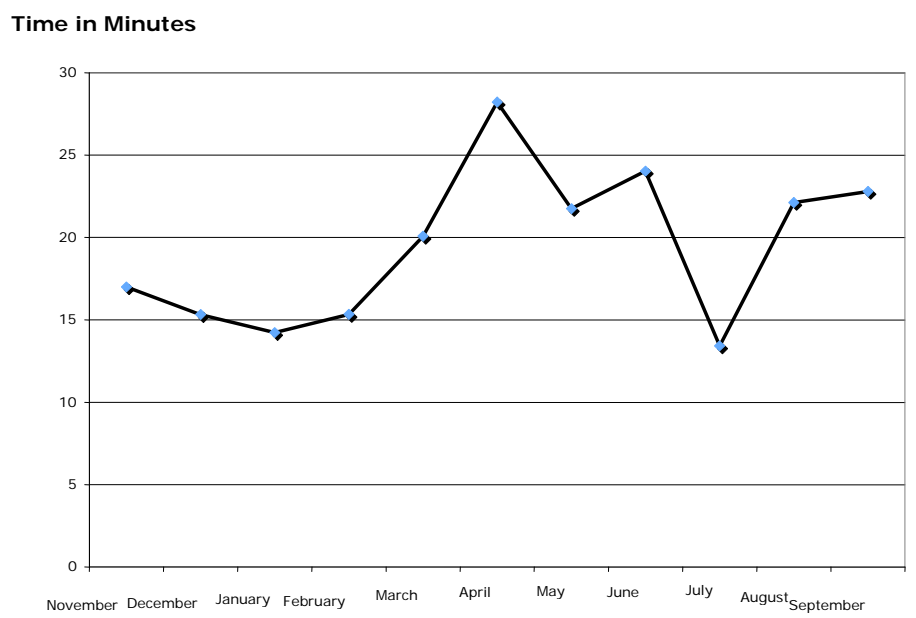

\section{Figure 7. Travis AFB Main Pharmacy Patient Processing Times by Month (FY08)}

A potential congestion in the operations occurred at the two fill stations within the pharmacy during the research team's visit to Travis. When the prescription orders are passed back in the process line from the two receiving windows, they are funneled to two fill stations that are located one behind the other. Time is wasted in determining which station processes what order. The problem is minimal when the process flow is light, but when orders increase, the first station gets backed up. A relatively simple redesign of the layout will reduce such congestion.

\subsubsection{Annex Pharmacy}

The annex pharmacy is designed to service only script and initial refill patients seen by civilian healthcare providers. The pharmacy predominately services retirees, primarily because it is located next to the PX. The monthly service volume is depicted in Table 8 and divided into script patients, POE patients, and refill patients. As seen in Table 8, the pharmacy is not only servicing its script patients but also POE and refill patients. The refill patients could have called in their refill so their order could be serviced from the refill pharmacy, and the POE patients could have been serviced from the main pharmacy. The workload indicates that almost $12 \%$ of the patients seen are ones that should be seen at the main or the refill pharmacy. 


\begin{tabular}{|c|c|c|c|c|}
\hline Month & Script Walk-in & Provider Entry & Refill Walk-in & Total \\
\hline October & 5983 & 204 & 807 & 6994 \\
\hline November & 5633 & 174 & 561 & 6368 \\
\hline December & 5485 & 136 & 468 & 6089 \\
\hline January & 6306 & 274 & 565 & 7145 \\
\hline February & 6201 & 362 & 566 & 7129 \\
\hline March & 6579 & 401 & 693 & 7673 \\
\hline April & 6237 & 363 & 724 & 7324 \\
\hline May & 5997 & 373 & 904 & 7274 \\
\hline June & 5798 & 413 & 733 & 6944 \\
\hline July & 5607 & 402 & 814 & 6823 \\
\hline August & 5999 & 475 & 819 & 7293 \\
\hline September & 6002 & 505 & 843 & 7351 \\
\hline Total & 71828 & 4082 & 8497 & 84406 \\
\hline Avg/Month & 5986 & 340 & 708 & 7034 \\
\hline
\end{tabular}

Table 8. Travis AFB Annex Patient Volume Report by Month

Figure 8 shows the monthly average processing time is significantly more than the pharmacy's target of 20 minutes. If the main pharmacy only processes the POE patients and the annex pharmacy only processes the script patients, the annex pharmacy would receive 340 less POE patients but 192 more script patients per month. By sending refill patients to the refill pharmacy, the net reduction of patients would be more than $12 \%$ at the annex pharmacy. Also, reassigning two pharmacy technicians from the main pharmacy to the annex will benefit the annex operation without having an adverse effect on the main pharmacy. With the reduction in patient traffic and added pharmacy technicians at the annex pharmacy, the processing time will be much shorter and should be within the command's goal of 20 minutes on average. Refill patients can be more effectively served by the refill pharmacy at a much lower cost and with virtually no waiting time for patients. 


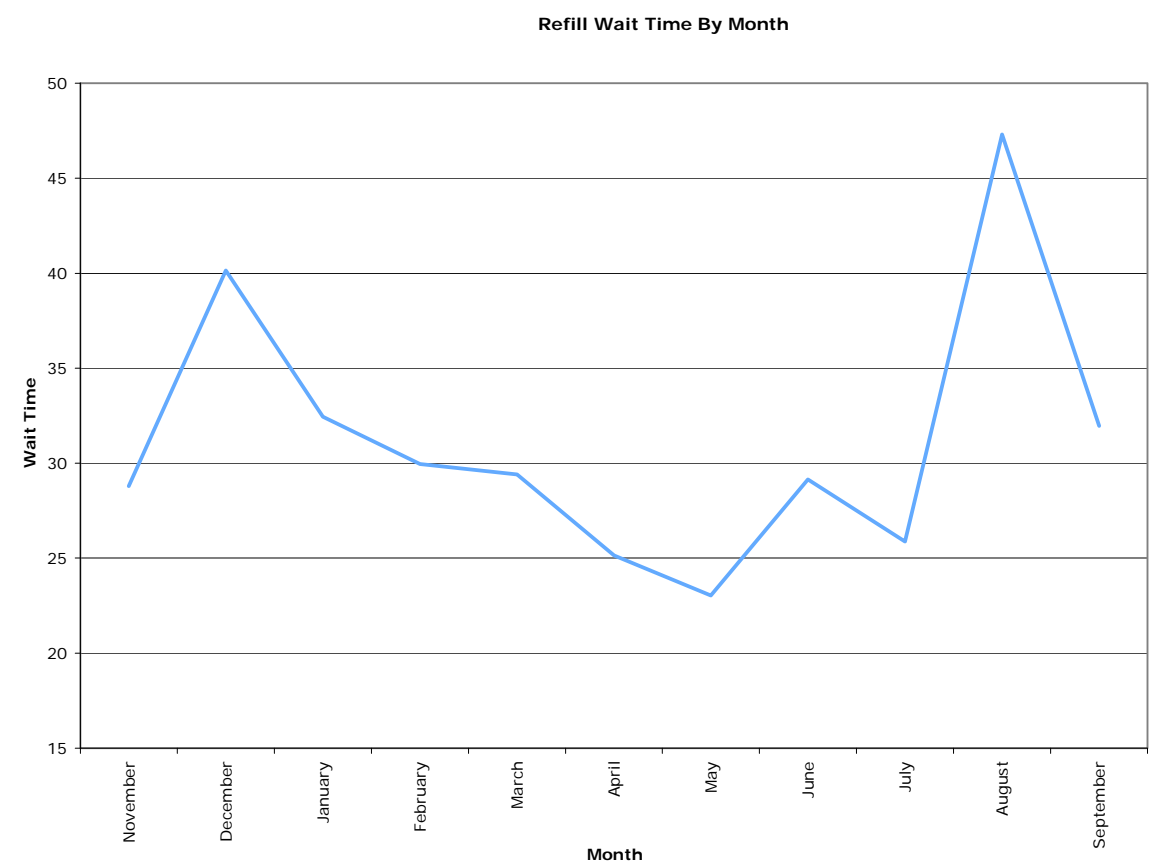

Figure 8. Travis AFB Annex Patient Processing Times by Month (FY08)

Another item for discussion in the annex pharmacy is the basic workflow setup. There is a large bottleneck at the order processing station for the manual input of all scripts. There is only one technician working the station and only one computer assigned for that process. If another computer and a technician were allocated for that process, at least during peak operations, then the average time spent at that station of 5 minutes could feasibly be cut in half.

\subsubsection{Refill Pharmacy}

The second floor of the main pharmacy houses the refill order filling process for the refill annex pharmacy. The second floor is accessible from the main pharmacy by an elevator. Both the main pharmacy and the second floor refill operation house their own stock of medications to process orders for their daily operation. The refill pharmacy starts downloading orders from the call-in system at 0800 hours in the morning and finishes with their last download of orders at 1300 hours. 
Refill patients must utilize the call-in system to place their order request before 1300 hours the day prior to picking up their medication at the annex. Any order called into the system after 1300 hours will not be processed for a next-day pickup but will be ready the day after. For example, a refill called in at 1400 hours on Wednesday would not be ready for pickup until Friday. However, if it had been placed at 1200 hours on Wednesday, it would be ready for pickup on Thursday.

The refill pharmacy has no variability in its operations and has no face-to-face interaction with patients. The daily orders averaged about 1,200 prescriptions and are processed by just six personnel. Thus, the workload per technician is much higher for the refill operation at 200 orders per person compared to the main pharmacy at 40 and the annex at 47 . The refill pharmacy should be able handle the additional workload of 1,250 refills per month without adding additional resources, which is currently serviced at the main and the annex pharmacies.

The refill pharmacy operations look like a standardized manufacturing assembly line. Note that the "standardization" is one of the 5-S methodologies in Lean Production, as discussed in Section 2.1. Technicians can focus on filling prescriptions without interruption. If the process variability created by the random arrival pattern of patients and interaction with patients were removed from the system, productivity would significantly increase. According to the queueing theory, the patient processing time is heavily dependent on the variability (or the distribution) of the patients' arrival pattern. (e.g., Kleinrock, 1975). This explains the efficiency in the refill pharmacy and the mail-order program.

\subsubsection{Summary and Recommendations for the Travis AFB Pharmacies}

If the pharmacy chose to enforce the use of the annex and refill pharmacies for all script and refill patients, then the main pharmacy would enjoy a total reduction in patient processing time of approximately 7 minutes. The main hospital pharmacy should enforce the use of the latter two facilities for script and refill patients. 
The main pharmacy can potentially reduce the number of personnel while maintaining the same level of customer service. However, for a more concrete recommendation, more data on customer arrival times needs to be collected to fit to the right distribution. The patient processing time is very sensitive to the variability of the patient's arrival pattern (or distribution of the inter-arrival times).

For the Travis annex pharmacy, it is not feasible to reduce personnel in order to maintain the current level of services provided. By reassigning two pharmacy technicians from the main pharmacy to the annex pharmacy and by shifting refill orders to the refill pharmacy, both pharmacies would significantly improve productivity and reduce customer processing times.

The authors' survey revealed that despite the ability of patients to call-in or fax refill scripts beforehand, many customers either choose not to do so or are unable to do so because of the complexity of the system. A technician or volunteer assigned to assist these customers directly would also serve to alleviate this aforementioned backlog, thus decreasing overall processing times.

\subsection{Defense Language Institute (DLI) Pharmacy}

The DLI pharmacy, the smallest of the three that we visited, was chosen to be representative of all clinic pharmacies throughout the military due to the population served by this and most other clinics. The clinic pharmacy employs two military pharmacy technicians and two civilian pharmacists (GS). The clinic maintains less than 300 line items of inventory and spends an average of $\$ 90,000$ per month on medications. The facility processes an average of 200 drug orders per day and 4,500 per month. The four employees process an approximate total of 50 orders per employee per day. The personnel cost of the four employees is a total of $\$ 14,627$ per month with a total of 4,500 scripts processed. This would value the cost of processing each script without considering drug costs or other overhead costs at $\$ 3.25$ per order. This figure is slightly higher than that of the Travis main or the 
annex pharmacies, but there is no surprise since it is a much smaller facility with less automation.

The average wait times for patients waiting just to drop off prescription requests ranges from 2 minutes to 25 minutes, with a mean of 15 minutes given the current operational configuration. Approximately $25 \%$ of the pharmacy's business comes from walk-in script requests from civilian healthcare providers. A bottleneck at the receiving station is caused by this $25 \%$ of personnel since these scripts must be manually typed into the system and transcend through the entire process flow, causing a longer wait time than would normally occur.

The primary data collected from the DLI were the patient process times from physically observing patients at the pharmacy, patient service volume reports collected from the pharmacy for the entire fiscal year 2008, and financial expenditures on medications. The volume report as shown in Table 9 reflects patient data broken down into three categories: POE, script patients from civilian healthcare providers and refill patients. The script patients were further broken down into retirees and pediatric patients. Neither retirees nor children are seen at the DLI clinic. The refill patients are broken down into either military patients or civilians. The months of August and September were forecasts based on a trend analysis of all the prior months. Monthly totals and the average for each type of patient are shown in Table 9. 


\begin{tabular}{|c|c|c|c|c|c|c|c|c|}
\hline Month & Total & Military & Civilian & Pediatric & Refill & $\%$ POE & \% Scripts & $\%$ Refill \\
\hline October & 4374 & 2135 & 1324 & 190 & 725 & $48.81 \%$ & $34.61 \%$ & $16.58 \%$ \\
\hline November & 3830 & 1885 & 1106 & 164 & 675 & $49.22 \%$ & $33.16 \%$ & $17.62 \%$ \\
\hline December & 3562 & 1828 & 853 & 190 & 691 & $51.32 \%$ & $29.28 \%$ & $19.40 \%$ \\
\hline January & 4390 & 2311 & 1254 & 204 & 621 & $52.64 \%$ & $33.21 \%$ & $14.15 \%$ \\
\hline February & 5389 & 3040 & 1431 & 223 & 695 & $56.41 \%$ & $30.69 \%$ & $12.90 \%$ \\
\hline March & 4820 & 2769 & 1175 & 229 & 363 & $57.45 \%$ & $29.13 \%$ & $7.53 \%$ \\
\hline April & 5247 & 3305 & 1129 & 169 & 644 & $62.99 \%$ & $24.74 \%$ & $12.27 \%$ \\
\hline May & 4550 & 2774 & 927 & 178 & 671 & $60.97 \%$ & $24.29 \%$ & $14.75 \%$ \\
\hline June & 4082 & 2351 & 805 & 130 & 796 & $57.59 \%$ & $22.91 \%$ & $19.50 \%$ \\
\hline July & 4871 & 3067 & 933 & 168 & 647 & $62.97 \%$ & $22.62 \%$ & $13.28 \%$ \\
\hline August & 4951 & 3183 & 898 & 165 & 645 & $64.29 \%$ & $21.46 \%$ & $13.04 \%$ \\
\hline September & 5031 & 3299 & 862 & 161 & 644 & $65.57 \%$ & $20.34 \%$ & $12.80 \%$ \\
\hline TOTAL & 40244 & 22398 & 10004 & 1677 & 5881 & & & \\
\hline AVG & 4472 & 2489 & 1112 & 186 & 653 & $57.52 \%$ & $27.20 \%$ & $14.48 \%$ \\
\hline
\end{tabular}

Table 9. The DLI Patient Volume Report (Provided by the DLI Pharmacy)

The second type of data collected at the DLI is the patient wait times at the receiving window. There is no special priority for patients waiting in line to be seen at the receiving window or within the pharmacy. However, there is a difference in process time between script patients compared to POE and refill patients. POE and refill patients could normally be served at the pharmacy receiving window in less than one minute while the script patients would take from 2 to 20 minutes at the same window, based on the amount of paper scripts.

The non-value-added wait time was not only experienced by the script patients but also by the other type of patients waiting in line due to the bottleneck created at the single receiving window that processes script orders. The crux of the problem was the time it took for the pharmacy technician to type into the system every medication script a patient had and to verify the prescribing physician's Drug Enforcement Agency prescriber number. This was a very tedious process in order to get each medication required for the script patient. The significant non-value added time could be eliminated if script patients could call-in their prescription requests in the afternoon the day prior to coming in to pick up their medications. The addition of call-in capability will substantially reduce patients' waiting times.

At the time of our visit to the DLI pharmacy, the addition of the third patient service window was considered to reduce patient processing time. The additional 
window would come in the form of a second receiving window or second dispensing window. Based on the information collected at the facility, with the number of patients seen daily and the processing times for all processes within the pharmacy, there would be no added benefit to the patients to add a third window, i.e., there would be no reduction in patient processing time as a result. Due to the size of the facility and the number of employees working at the facility, it was not possible to recommend any personnel reductions or increases.

We did identify one potential area of improvement within the DLI pharmacy that may decrease patient processing times within the system. This was a longer processing time for patients seen by civilian doctors. The civilian scripts took a significantly longer time to process and caused a subsequent bottleneck in the waiting line for all patients. A call-in procedure should be adopted by the pharmacy for all script patients that will ensure that patient data is entered into the computer system prior to their arrival. This would eliminate some of the variability in processing times for the DLI pharmacy, affording all patients an identical processing system with no additional steps or processes. This procedural change would yield a total average processing time reduction of 9 minutes for script patients and 3 minutes for all patients. Additionally, we suggest the refill patients be serviced by the mail-order pharmacy (e.g., TMOP), which can serve them more economically and efficiently. In the mean time, while the DLI implements the call-in system, priority queueing on POE patients similar to express checkout queues commonly seen at many grocery stores (i.e., higher priority for customers with smaller expected processing times) should be implemented.

\subsection{Balboa Naval Medical Center San Diego Pharmacy}

Naval Medical Center San Diego (Balboa) has two pharmacies: the main hospital pharmacy and the refill pharmacy that is outsourced to the Veterans Affairs (VA) consolidated mail outpatient pharmacy (CMOP). There are 11 supporting branch clinics in the San Diego Naval Base area, but they are not included in our study. 


\subsubsection{Balboa Main Pharmacy}

The main pharmacy is designed to serve as a pharmacy for a large medical center and to service POE and script patients only. The pharmacy maintains more than 2,500 line items of inventory and spends an average of $\$ 2.1$ million per month on medications. The facility processes an average of 1,600 drug orders per day, or approximately 40,000 per month. The pharmacy employs more than 24 personnel to do direct day-to-day outpatient operations. Balboa Medical Center Pharmacy was not as forthcoming with their personnel as the other facilities about the amount of contractors versus GS employees and military that work within the pharmacy. Thus, we were unable to conduct the unit labor cost computation for a comparison purpose with other facilities.

Both POE and script patients enter the system by pulling an electronic number and then waiting to be called to one of eight registration windows. The registration windows perform three functions: registration, receiving scripts, and dispensing medications. Patients in uniform receive no special privileges, and the registration process can last between three to five minutes, depending on the patient type and the number of prescriptions in their order. The registration processing times were provided by the deputy pharmacist during the team's visit to the Balboa pharmacy.

When a patient enters the system, a waiting time is given to the type of patient in a queue management software platform, called Q-flow, starting from the time of the pulled ticket. While the patient waits in the waiting room, the registration clerk prints the drug order and labels to a printer next to the drug-pull station. There are two technicians working at the station that continuously fill patient orders. The prescription orders are pulled for three varieties of drugs: narcotics from the vault, drugs from the shelf, and automatically dispensed drugs from the Pharmacy 2000 dispensing cabinet. Depending on the type of drug needed for the order and the number of drugs in an order, the fill time can last between 1 to 5 minutes. 
Once the pharmacy technician has finished filling the order it is passed to the pharmacist station. There, a pharmacist is in charge of verifying every order to ensure that it has been filled correctly. The time associated with this quality control process can vary depending on the number of drugs being dispensed, whether a narcotic is involved, and whether the medication is a pediatric drug. This process normally takes between 1 to 3 minutes.

Once the pharmacist is finished with validating the order, it is passed to the registration clerk for issuance. The clerk calls up the patient by their ticket number and closes out the patient processing time in Q-flow.

The depiction in Figure 9 demonstrates patient processing time with Q-flow. The stated goal of the Balboa pharmacy was to have a reduced total processing time and have that time at or below 20 minutes. There was also an overall increase to total patient processing time around January 2008 when the Q-flow system was implemented. The Q-flow system that is used during the patient registration process appears to have added an average of six minutes to the overall patient processing time. The other two pharmacies in the study do not utilize this system for queueing and tracking patients. The benefits of using this system are the ability to track each type of patient and their category's processing time and to know exactly how many patients are receiving scripts; however, the downside is that the patients must wait an average of six additional minutes for their medication while their information is inputted into the Q-flow. The other two pharmacies could only show total script volume by patient type and were tracking patient processing times off-line to prevent artificial wait time being added to the patients' wait for their medication. 


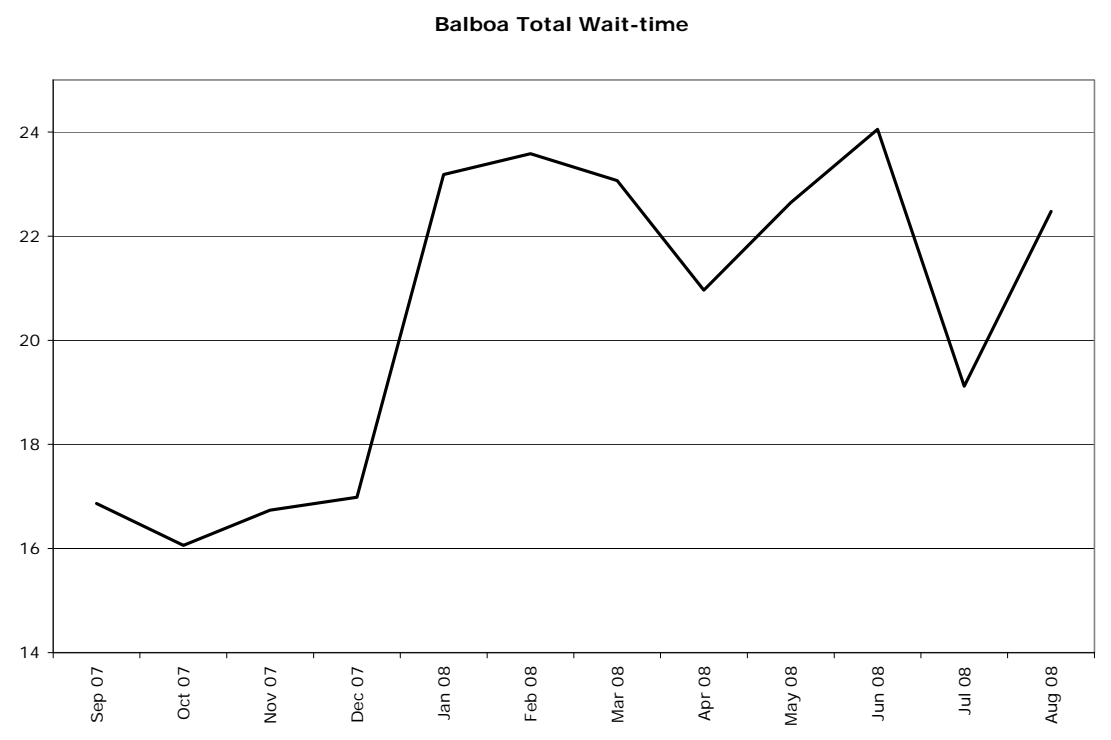

Figure 9. Balboa-Patient Processing Times by Month

During our visit, we observed a potential bottleneck in the operation, which occurred at the fill stations within the pharmacy. When the prescription orders were passed back from the registration window, they fed from up to eight registration windows into one fill process-line, consisting of two fill stations. Also, there was a potential for a large backlog of orders into a single printer and only two workers filling prescriptions from eight registrations windows. This was not a problem when patient flow was light, but when orders increased, the fill station could become inundated. The addition of a fill station, a pharmacist's station, and two or three printers would significantly eliminate the bottleneck and reduce patients' waiting time.

\subsubsection{Consolidated Mail Outpatient Pharmacy (CMOP) for Refills}

No refill patients are physically seen at the registration window of the main pharmacy. All refill operations are outsourced to the Veterans Affairs (VA) consolidated mail outpatient pharmacy (CMOP) mail-order refill facility. The CMOP program processes an average of 50,000 line-item requests for medications a month, servicing approximately 20,000 patients. CMOP handles $80 \%$ of all refills to be mailed, and the hospital mails $5 \%$ of refills that cannot be serviced by CMOP due to the type of medication. The remaining $15 \%$ of refills are handled at other military 
pharmacy locations throughout the San Diego area. The Balboa pharmacy is charged a flat rate processing fee of $\$ 2.85$ per refill, a total of $\$ 1.71$ million per year based on 50,000 refill orders per month plus the cost of medications.

It is not the purpose of this study to evaluate the performance of CMOP but separating refill patients from the main pharmacy is the right approach. By doing this, the main pharmacy can concentrate on its primary function of supporting the hospital mission and improving customer service while refill customers do not need to waste their time waiting in line. Refills can be more economically serviced by a refill-only pharmacy, as discussed in the previous section.

However, the Balboa pharmacy has not reduced any personnel since moving refills to CMOP and has actually hired more personnel since implementing CMOP in 2002. The Balboa hospital should ideally have conducted a cost analysis and personnel utilization study to properly determine the optimum manning-needs of the pharmacy after the change in operations. The fact that CMOP handles approximately 2,000 scripts a day while the hospital handles 1,600 scripts a day means that the hospital reduced its workload by at least half with no subsequent reduction in labor. 


\section{$5.0 \quad$ Inventory Management Issues}

Inventory management appears to be an important issue for the Travis pharmacies. During our visit to the Travis AFB pharmacies, we noted that they did not use any inventory management tools or economic order quantity policies. The medical logistics personnel at the hospital are in charge of all resupply of pharmaceutical lines within all pharmacy areas. They perform a daily scan of pharmaceutical line-item locations by barcode and visually determine how many to reorder based on the available space for more items at that specific location. This process is repeated for all locations on a daily basis. Once all scans are completed for the day, the scanner is cradled at the medical logistics ordering computer and all the reorders are downloaded and processed for that day with the prime vendor. The ordering was not performed based on the days of supply or economic order quantity but on prior utilization and forecasted use. Their ordering was based on need and the daily scanning procedure. Neither Travis pharmacy personnel nor the medical logistics personnel were aware of exactly how many line items were stocked in the pharmacy. When asked who performed the inventory management of the pharmaceutical lines stocked within the main pharmacy, pharmacy personnel said it was the logistics personnel and logistics personnel said it was the pharmacy personnel who performed that operation. This again does not clearly demonstrate that there is any inventory management within the main pharmacy. The perception is that each believes the other is performing that mission, which contributes to a trend for increasing prime vendor and credit card expenditures.

Inventory management is an essential key to keeping costs down in the pharmacy. The stock rotation of medication must occur at each inventory item location to ensure the first-in-first-out (FIFO) concept is applied and to avoid expiration of potency and dated medications. The pharmaceutical expenditures from the prime vendor and on the government credit card could further indicate that proper inventory management is not being used at the Travis pharmacy. However, 
a much larger determinate of the problem is the pharmaceutical returns that are credited back to the credit card. Below are the prime vendor and credit card expenditures for fiscal year 2008 that include the pharmaceutical returns for credit in Table 10. There was more than $\$ 1$ million dollars worth of pharmaceuticals returned for money during the fiscal year. Any one of the leading pharmaceutical return companies will take expired or about-to-be expired pharmaceuticals for a fraction of the cost for which they were originally procured. If there were a generous rate of 25 cents per dollar given for all Travis returns to the return company, then there would have been over $\$ 4.2$ million of pharmaceuticals turned in annually. The pharmaceutical returns show the need for good inventory management and a significant savings to the pharmacy of at least the $\$ 4.2$ million worth (potentially much more) of turned-in pharmaceuticals every year. This is more than $16 \%$ of the annual expenditure to purchase drugs. Although we were unable to obtain the pharmaceutical return amount data from the DLI or Balboa pharmacies, they may face the same problem.

\begin{tabular}{|l|r|r|r|r|}
\hline & Prime Vendor & \multicolumn{1}{|c|}{ Credit Card } & \multicolumn{1}{c|}{ Total } & \multicolumn{1}{c|}{ Returns } \\
\hline OCT & $\$ 2,086,271.50$ & $\$ 64,795.63$ & $\$ 2,151,067.13$ & $-\$ 13,526.81$ \\
NOV & $\$ 1,728,548.54$ & $\$ 139,005.98$ & $\$ 1,867,554.52$ & $-\$ 103,785.79$ \\
DEC & $\$ 2,148,571.13$ & $\$ 1,332.78$ & $\$ 2,149,903.91$ & $-\$ 116,095.18$ \\
JAN & $\$ 2,272,247.16$ & $\$ 11,716.03$ & $\$ 2,283,963.19$ & $-\$ 151,913.52$ \\
FEB & $\$ 1,907,518.24$ & $\$ 57,063.17$ & $\$ 1,964,581.41$ & $-\$ 32,003.90$ \\
MAR & $\$ 1,936,848.30$ & $\$ 204,780.93$ & $\$ 2,141,629.23$ & $-\$ 113,573.37$ \\
APR & $\$ 2,117,087.14$ & $\$ 198,500.45$ & $\$ 2,315,587.59$ & $-\$ 9,424.02$ \\
MAY & $\$ 2,020,312.92$ & $\$ 111,234.68$ & $\$ 2,131,547.60$ & $-\$ 67,359.69$ \\
JUN & $\$ 2,226,920.00$ & $\$ 41,031.72$ & $\$ 2,267,951.72$ & $-\$ 61,916.35$ \\
JUL & $\$ 2,232,747.09$ & $\$ 75,611.69$ & $\$ 2,308,358.78$ & $-\$ 174,374.21$ \\
AUG & $\$ 2,192,021.85$ & $\$ 112,810.81$ & $\$ 2,304,832.67$ & $-\$ 103,229.42$ \\
SEP & $\$ 2,214,624.51$ & $\$ 116,866.00$ & $\$ 2,331,490.51$ & $-\$ 106,653.44$ \\
\hline Total Spent & $\$ 25,083,718.39$ & $\$ 1,134,749.87$ & $\$ 26,218,468.26$ & $-\$ 1,053,855.70$ \\
\hline
\end{tabular}

Table 10. Travis AFB Pharmacy-Total Expenditures for FY2008

Since the prime vendor makes a daily delivery, the pharmacy does not need to keep high inventory. During the research team's visit to the pharmacy, we observed that the newly-arrived items were stacked on top of the current inventory, creating a very undesirable last-in-first-out (LIFO) system. Ideally, the information 
system should be able to keep track of the shelf-life of each drug so that the inventory could be rotated before the expiration date. The stock rotation can be done within the base hospital pharmacies (main, annex and refill pharmacies) as well as through the prime vendor. This should be part of the contract with the prime vendor. The prime vendor will replace the items after a certain period of time but long before the expiration date. The prime vendor, on the other hand, can find demand for the drugs with other customers using its vast distribution network. The improvement can be immediately realized if the inventory clerk strictly enforces firstin-first-out (FIFO) inventory policy. In fact, this can be done with practically no cost and with minimal training of the pharmacy clerks.

We also collected and reviewed the DLl's financial expenditures on medications for the entire fiscal year. The expenditures are broken down into two categories: credit card purchases and prime vendor purchases. The Defense Logistics Agency (DLA) negotiates the prime vendor contract for the entire western region of the United States and is a joint-services contract for all healthcare facilities within the region. The negotiated price is based on a joint pharmacy formulary of medications and a federal supply catalog of pricing for each type of medication. The contract is the best price the DoD can secure for its pharmacies to avoid facilities in certain geographical areas from paying higher prices. The contract also reduces the need to carry excessive amounts of inventory because it mandates a 95\% minimum fill rate on all requests as well as next day delivery of all orders. However, having the contract in place does not mean that there is no need for the pharmacy to practice good inventory management.

The biggest indication of a potential inventory problem is the use of the government credit card to procure drugs, as is the case in Travis AFB pharmacies. The use of the government credit card is reserved for one-time procurements and for emergency need items. The use of the card, especially through the latter half of the year, demonstrates an issue with ordering supplies from the prime vendor. Again, the use of a prime vendor does not negate the need for inventory management, but 
it does help to defray the cost of pharmaceuticals. This is why most pharmaceutical government credit card purchases should only be conducted on an emergency basis since purchasing pharmaceuticals with the credit card does not have the benefit of reduced-cost like purchasing through the prime vendor. As shown in Tables 10 and 11, both Travis and the DLI have a similar purchasing problem with the government credit card. Travis charged $4.5 \%$ of its total annual expenditures to the government credit card and the DLI charged 3.1\%. We were unable to obtain the government credit card expenditure information for the Balboa pharmacy.

Balboa, Travis, and the DLI all utilize the same prime vendor for pharmaceutical resupply. The vendor provides next-day delivery to the pharmacy. They order using DMLSS; however, the main issue with DMLSS is its ability to manage inventory and establish an economic order quantity for reordering through the prime vendor. DMLSS will track historical orders placed for a particular drug, but drugs are not dispensed in the unit of issue in which they are purchased. Thus, all three facilities attempt to manage inventory off-line through some "paper and pencil" process. They should implement an automated inventory-management system and strictly enforce FIFO when replenishing inventory. We also suggest that all three pharmacies, Balboa, Travis, and the DLI, implement an automated inventorymanagement system and collaborate with the prime vendor on stock rotation to minimize return amounts due to shelf-life expiration. 


\begin{tabular}{|c|c|c|c|}
\hline & PV & CC & Total \\
\hline OCT & $\$ 91,828$ & $\$ 1,333$ & $\$ 93,161$ \\
NOV & $\$ 61,239$ & $\$ 1,317$ & $\$ 62,556$ \\
DEC & $\$ 89,958$ & $\$ 1,007$ & $\$ 90,965$ \\
JAN & $\$ 91,199$ & $\$ 2,052$ & $\$ 93,250$ \\
FEB & $\$ 89,796$ & $\$ 191$ & $\$ 89,987$ \\
MAR & $\$ 82,091$ & $\$ 5,906$ & $\$ 87,997$ \\
APR & $\$ 97,869$ & $\$ 2,869$ & $\$ 100,738$ \\
MAY & $\$ 93,558$ & $\$ 1,376$ & $\$ 94,935$ \\
JUN & $\$ 82,898$ & $\$ 4,340$ & $\$ 87,238$ \\
JUL & $\$ 92,378$ & $\$ 3,915$ & $\$ 96,292$ \\
AUG & $\$ 93,510$ & $\$ 4,244$ & $\$ 97,754$ \\
SEP & $\$ 94,642$ & $\$ 4,574$ & $\$ 99,217$ \\
\hline TOTAL & $\$ 1,060,966$ & $\$ 33,124$ & $\$ 1,094,090$ \\
\hline
\end{tabular}

Table 11. The DLI's Total Pharmaceutical Expenditures for FY2008 Prime Vendor (PV) and Credit Card Purchase (CC) 
THIS PAGE INTENTIONALLY LEFT BLANK 


\subsection{Conclusions and Recommendations}

\subsection{Summary}

The escalating costs of healthcare are a fact of life for the US. The total cost of the military also continues to rise with the biggest percentage of this growth coming from its healthcare system. The military must internally attempt to lower costs before the consequences of inaction are amplified through congressional oversight. Congress has already added to the military's overall healthcare costs with the TRICARE for Life program and extended reservist eligibility for TRICARE. The Congressional Budget Office (CBO) has forecasted growth of $3 \%$, and a subsequent deficit to the system is estimated at a cost of approximately $\$ 38.4$ billion (CBO, 2006).

Since 2001, pharmacies have seen significant increases in customers and, subsequently, costs. Congress has mandated using civilian business organizations as benchmarks to improve efficiency in the hopes of saving money within the military. One possible tool to assist in lowering some of the overall healthcare costs is the implementation of Lean Six Sigma methodology within all pharmacies in our Medical Treatment Facilities. This implementation would yield quantifiable benefits in efficiency, manpower, and pharmaceutical cost savings.

We visited three pharmacy facilities for this research: the Defense Language Institute medical clinic pharmacy, the Travis Air Force Base Hospital, and the Balboa Naval Medical Center San Diego.

\subsection{Conclusions}

1. The DLI pharmacy operation was analyzed to determine the possibility of reducing patient processing time by adding receiving and/or dispensing windows. We determined that adding one window in dispensing or receiving had no effect on patient processing time. However, instituting a call-ahead system for refill scripts will potentially 
reduce the processing time by 5 minutes. The new call-ahead process will alleviate the bottleneck at the receiving window.

2. The two pharmacies we studied at Travis AFB were the hospital main pharmacy and the PX annex pharmacy. We analyzed both to reduce patient processing time and possibly save money in manpower. By enforcing the practice of serving only POE patients at the main pharmacy and script patients at the annex pharmacy and by sending refill patients to the refill pharmacy, the Travis pharmacies would see an overall reduced processing time.

3. The patient processing time at the Travis AFB annex pharmacy was a significant issue. The average total processing time was in excess of 45 minutes, partly due a bottleneck at one computer terminal for the input of new patient scripts. Also, the pharmacy seems to experience a lack of personnel working in the pharmacy. Our model showed a significant reduction in processing time for the patients with an increase of two personnel and an increase in one computer terminal for input of new patient scripts. These two technicians could be reassigned to the main pharmacy. Thus, with no cost to the DoD, the annex pharmacy should be able to improve its customer service.

4. Inventory management is a major problem area with significant opportunity for improvement. Newly-arrived pharmaceutical items are stacked on top of the current inventory, which increases the amount of shelf-life expired medications. Travis AFB pharmacy receives over \$1 million a year in pharmaceutical returns for expired medications. This is a significant amount of money since reimbursement is usually just a fraction of the original cost of the medication. This highlights that medications are simply shelved without regard to shelf-life of the drug or an effort to rotate stock. By implementing a better inventorymanagement system and by avoiding shelf-life expired drugs, the DoD can potentially save millions of dollars a year from one medium-size pharmacy alone. The improvement can be immediately realized if the inventory clerk strictly enforces a first-in-first-out (FIFO) inventory policy. In fact, this can be done with practically no cost and with minimal training of the pharmacy clerks. The savings will be significant if the DoD implements a better inventory-management system in all its pharmacies.

5. The Balboa pharmacy is the only facility that does not service refill prescriptions, which it outsources to CMOP at a flat service-cost of $\$ 2.85$ per prescription, in addition to the cost of the medication. This is a significant amount when it is considered that CMOP handles well over 50,000 refills a month. The separation of refill orders from the main pharmacy is the right approach. However, the Balboa pharmacy 
should conduct a manpower analysis study for the post-institution of the CMOP program. The facility has retained all personnel employed prior to the implementation of the CMOP program.

\subsection{Recommendations}

1. What remained a constant with all the facilities we visited was a lack of pharmaceutical inventory management. The primary ordering mechanism for each of the facilities was Defense Medical Logistics Standard Support (DMLSS). DMLSS orders from the regional pharmaceutical prime vendor by prime vendor number and a standard unit of issue that will always arrive in the biggest unit of issue, i.e., one case or one box of something. Often, the need for a particular item is much less than the biggest unit of issue. DMLSS as a stand-alone unit does not have the capability to manage inventory down to the smallest unit of issue, i.e., one bottle of aspirin. This shortcoming highlights the need for better automation to perform true inventory management in the DoD pharmacies as a whole. Since the Lean doctrine has pushed for the elimination of warehouses and since there is a contractual requirement for next-day deliveries from the prime vendor, it is much more difficult to order what is needed for day-to-day use. Thus, all the facilities are maintaining stocks that far exceed their need between shipments from their prime vendor. Travis and Balboa are making an effort to keep on-hand stocks to a minimum by using hand-held scanners for daily inventories and manual stock records to track order history by line item. However, both efforts were falling short of truly maintaining a good inventory management of all their lines of stock.

Travis operates two separate stock areas (the main and the refill stock areas) in the same building to provide pharmaceuticals to the main pharmacy operation and the refill annex facility. The stock consolidation should be considered to achieve inventory cost savings. Stock consolidation, or inventory pooling, will reduce the safety stock level, but there could be extra transportation or capital investment cost. Thus, a careful trade-off study should be conducted.

2. The biggest obstacle in retaining process improvements in the military is the constant turnover due to reassignment. One way to ensure change is to develop a document in the form of a standard operations procedure manual, or SOP. The SOP would then be maintained, updated and considered to be a living document. Every hospital requires that each employee attend annual training during his or her birth month. Pharmacy SOP training should be incorporated into that training as well as requiring the training for all new personnel. The institution of the pharmacy's procedures will help cement them for the 
long-term. Since the turnover of military essentially cycles at a rate of every three years, the key to long-term entrenchment or continuity is through the civilian workers of each pharmacy. Every employee must read, know and understand the entire SOP to ensure the best implementation of the key processes. Training in the facilities should be ongoing as well, and standard procedures should be the central component of that training.

3. Almost every military organization has the tendency for building a bureaucracy or empire around one's command structure. To combat this tendency in future leaders and ensure continued personnel savings, the manpower section of the hospital should also routinely perform a job-position audit of all the positions within each pharmacy. This process would cement the proposed/new manning configurations of each facility and officially document what personnel are required to operate each facility.

4. The Travis main pharmacy incorporates an excellent personnel rotation process throughout the day. Every hour all personnel rotate from one station to another to prevent work monotony and ensure that all personnel are trained on all processes throughout the operation. This rotation keeps every employee engaged in all facets of the operation and thoroughly trains new personnel as well. Similar efforts should be followed at all pharmacies.

5. The efforts toward continuous improvement should be stressed throughout each pharmacy to include employee buy-in. Efforts like those implemented at the Travis main pharmacy exemplify continuous improvements and employee involvement. Tracking patient processing times for every patient processed and publishing the results is an excellent way to track total processing times and demonstrate to the public the pharmacy's concern with keeping the patients' main problem, processing times, to a minimum.

\subsection{Suggestions for Further Study}

Improving healthcare operations is simply too large and too important of a topic to ignore and is worthy of numerous studies. The current study, which addressed pharmacy operations at three sites, has simply scratched the surface of this issue. However, a number of issues identified during our research warrant further study. 
1. The DoD as well as civilian and government organizations have been moving toward increasingly automated ways of doing business. The use of DMLSS seems to be a step in the right direction; however, this system woefully falls short in the area of inventory management. MTF pharmacies, in general, have no standard means of tracking historical data in order to more accurately forecast usage and spending. In addition, each of the three pharmacies visited by the research team utilizes different dispensing procedures, software and/or equipment. Though there is much to be said for the difference in the size or service of each, there was little difference between their procedures.

2. In addition, there is an opportunity for load-leveling across facilities, or potential inventory pooling in order to eliminate waste, in the way of pharmaceutical returns as well as decreasing the risk of stock-outs of necessary medications. The authors contend that the potential for a common, inter-operable pharmacy system should be studied in order to estimate any added benefits of such a system. Much like the potential benefits of the DoD and commercial use of Total Asset Visibility (TAV) there may be similar opportunities for cost savings within pharmacy operations as well as the added benefits of standard procedures across the DoD.

3. Though it is a test program, Balboa's use of mail delivery of pharmaceuticals using CMOP appears to contribute significantly not only to greater convenience to the customer but also to cost savings. While similar programs exist elsewhere, not much has been documented. One possible reason for this is the manner in which funding for pharmacies and medical treatment facilities is allocated. Pharmacy staff may fear losing customers to these services and eventually losing the funding (and personnel) associated with less pharmacy usage. There may be considerable benefits to measuring and analyzing Balboa's perceived successes in cost savings and enforcing home delivery programs to the DoD pharmacies as a whole. More comprehensive research should be done to study the benefits of a mail-order system for refill orders.

4. Manpower issues also deserve closer examination since different pharmacies and hospitals seem to have different compositions of employees on their respective staff. As previously mentioned, we note that some pharmacies carry a larger composition of contracted employees than General Scale (GS) employees at a significantly higher cost. In addition, the GS employees carry still higher costs to these facilities relative to their active-duty counterparts. Determining the ideal employee composition in terms of contracted employees, GS employees, and active-duty personnel is a complex issue with many considerations. For example, the cost implications considerations are 
as mentioned above. In addition, one should also take into account the expertise and experience of these different employee types. Finally, the factors such as the routine 2-3 year rotation of active-duty personnel, the need for additional training, etc., must also be taken into account.

5. It should be kept in mind that no process improvement can be achieved overnight. While the Naval Postgraduate School research team is willing to help the DoD improve the pharmacy operations and reduce healthcare cost by providing technical consultation and training, the actual implementation of continuous process improvement cannot really be done without employee buy-in. The DoD must provide its employees with suitable training along with an incentive system so that they can voluntarily participate in the continuous process-improvement efforts. As with any organization, support from leadership and open communication is essential to process improvement. 


\section{List of References}

Apte, U. M., \& Goh, C. H. (2004, Fall). Applying lean manufacturing principles to information-intensive services. International Journal of Service Technology and Management, 5(5/6), 488-506.

Apte, U.M., \& Kang, K., (2008). "Lean Six Sigma for Reduced Cycle Time and Costs, and Improved Readiness", in E. Mrudula, ed., Lean Six Sigma: An Introduction, ICFAI University Press, Hyderabad, India. 107 -127.

CBO (Congressional Budget Office) (2006). Cost estimate of John Warner national defense authorization act for FY 2007. CBO Cost Estimate/H.R. 5122 Conference. Retrieved April 22, 2008, from http://www.cbo.gov/ftpdocs/76xx/doc7668/hr5122pgo.pdf

CBO (Congressional Budget Office) (2007). Long-term implications of current defense plans: Summary update for FY 2008. Retrieved April 22, 2008, http://www.cbo.gov/ftpdocs/88xx/doc8844/12-13-LT-Defense.pdf

CBO (Congressional Budget Office) (2008). H.R. 4986 national defense authorization act for FY 2008. CBO Cost Estimate. Retrieved April 22, 2008, from http://www.cbo.gov/ftpdocs/89xx/doc8950/hr4986.pdf

Coon, S.D. (2006). The MHS pharmacy benefit: Efficacy of civilian cost saving strategies (Master's Thesis). Monterey, CA: Naval Postgraduate School.

Dennis, P. (2002). Lean production simplified: A plain-language guide to the world's most powerful production system. New York: Productivity Press.

Esimai, G. (2005). Lean six sigma reduces medication errors. Quality Progress, 38(4), 51-57. Retrieved April 20, 2008, from ABI/INFORM Global database. (Document ID: 825035511).

Fairbanks, C.B. (2007). Using six sigma and lean methodologies to improve operating room (OR) throughput. AORN Journal, 86(1), 73-82.

General Electric. (2006). Commitment to quality. Retrieved August 8, 2006, from http://www.ge.com/en/company/companyinfo/quality/quality.htm

George, M.L. (2002). Lean six sigma: Combining six sigma quality with lean speed. New York: McGraw-Hill.

Goldratt, E.M., \& Cox J. (1992). The goal: A process of ongoing improvement (2nd revised ed.). Great Barrington, MA: North River Press.

Henning, T.D. (2008). Pharmaceutical cost containment through DoD's pharmaceutical dispensing system management (Master's Thesis). Monterey, CA: Naval Postgraduate School. 
Kelly, B. (2008, August 12). Tricare Mail Order Pharmacy Contract Officer, Pharmacoeconomic Center (PEC) in San Antonio. [Telephone interview with researchers].

Kleinrock, L. (1975). Queueing theory (Vol. 1: Theory). Wiley Interscience.

Koning, H., Verver, J.P.S., Heuvel, J., Bisgaard,S., \& Does, R. (2006). Lean six sigma in healthcare. Journal for Healthcare Quality, 28(2), 4-11.

Levinson, W.A. (2002). Henry Ford's lean vision: Enduring principles from the first Ford motor plant. New York: Productivity Press.

Nash, M., Poling, S.R., \& Ward, S. (2006). Using lean for faster six sigma results: A synchronized approach. New York: Productivity Press.

Nuce, J., Robinson, L., \& Sikora, T. (2008). Combating the military's escalating pharmacy costs: A lean six sigma approach (Master's Thesis). Monterey, CA: Naval Postgraduate School.

Paparone, C.R. (2008). A values-based critique of lean and six as a management ideology. Army Logistician, 40(1), 34-40.

Rath \& Strong. (2006). Rath \& Strong's six sigma pocket guide (new revised ed.). Lexington, MA: Rath \& Strong Management Consultants.

Stamatis, D.H. (2004). Six sigma fundamentals: A complete introduction to the system, methods, and tools. New York: Productivity Press.

Taylor, F.W. (1911). Principles of scientific management (paperback reprint, 1998). Mineola, NY: Dover.

Wikipedia (2009). Lean Manufacturing. Retrieved on April 29, 2009, from http://en.wikipedia.org/wiki/Lean_manufacturing.

Wikipedia (2009). Six Sigma. Retrieved on April 29, 2009, from http://en.wikipedia.org/wiki/Six_Sigma.

Womack, J.P., Jones, D.T., \& Roos. (1991). The machine that changed the world: The story of lean production. New York: Harper Collins.

Womack, J.P., \& Jones, D.T. (2003). Lean thinking. New York: Free Press. 


\section{3 - 2009 Sponsored Research Topics}

\section{Acquisition Management}

- $\quad$ Acquiring Combat Capability via Public-Private Partnerships (PPPs)

- BCA: Contractor vs. Organic Growth

- Defense Industry Consolidation

- $\quad$ EU-US Defense Industrial Relationships

- $\quad$ Knowledge Value Added (KVA) + Real Options (RO) Applied to Shipyard Planning Processes

- Managing Services Supply Chain

- MOSA Contracting Implications

- Portfolio Optimization via KVA + RO

- Private Military Sector

- Software Requirements for OA

- Spiral Development

- $\quad$ Strategy for Defense Acquisition Research

- $\quad$ The Software, Hardware Asset Reuse Enterprise (SHARE) repository

\section{Contract Management}

- Commodity Sourcing Strategies

- Contracting Government Procurement Functions

- Contractors in 21st Century Combat Zone

- Joint Contingency Contracting

- Model for Optimizing Contingency Contracting Planning and Execution

- Navy Contract Writing Guide

- Past Performance in Source Selection

- Strategic Contingency Contracting

- Transforming DoD Contract Closeout

- USAF Energy Savings Performance Contracts

- USAF IT Commodity Council

- $\quad$ USMC Contingency Contracting 


\section{Financial Management}

- Acquisitions via leasing: MPS case

- Budget Scoring

- $\quad$ Budgeting for Capabilities-based Planning

- $\quad$ Capital Budgeting for DoD

- $\quad$ Energy Saving Contracts/DoD Mobile Assets

- $\quad$ Financing DoD Budget via PPPs

- Lessons from Private Sector Capital Budgeting for DoD Acquisition Budgeting Reform

- $\quad$ PPPs and Government Financing

- ROI of Information Warfare Systems

- $\quad$ Special Termination Liability in MDAPs

- $\quad$ Strategic Sourcing

- Transaction Cost Economics (TCE) to Improve Cost Estimates

\section{Human Resources}

- Indefinite Reenlistment

- Individual Augmentation

- $\quad$ Learning Management Systems

- Moral Conduct Waivers and First-tem Attrition

- Retention

- The Navy's Selective Reenlistment Bonus (SRB) Management System

- Tuition Assistance

\section{Logistics Management}

- $\quad$ Analysis of LAV Depot Maintenance

- $\quad$ Army LOG MOD

- $\quad$ ASDS Product Support Analysis

- Cold-chain Logistics

- Contractors Supporting Military Operations

- Diffusion/Variability on Vendor Performance Evaluation

- Evolutionary Acquisition

- $\quad$ Lean Six Sigma to Reduce Costs and Improve Readiness 
- Naval Aviation Maintenance and Process Improvement (2)

- $\quad$ Optimizing CIWS Lifecycle Support (LCS)

- $\quad$ Outsourcing the Pearl Harbor MK-48 Intermediate Maintenance Activity

- $\quad$ Pallet Management System

- $\quad$ PBL (4)

- Privatization-NOSL/NAWCI

- RFID (6)

- Risk Analysis for Performance-based Logistics

- R-TOC Aegis Microwave Power Tubes

- Sense-and-Respond Logistics Network

- $\quad$ Strategic Sourcing

\section{Program Management}

- Building Collaborative Capacity

- $\quad$ Business Process Reengineering (BPR) for LCS Mission Module Acquisition

- $\quad$ Collaborative IT Tools Leveraging Competence

- Contractor vs. Organic Support

- Knowledge, Responsibilities and Decision Rights in MDAPs

- KVA Applied to Aegis and SSDS

- Managing the Service Supply Chain

- Measuring Uncertainty in Earned Value

- Organizational Modeling and Simulation

- Public-Private Partnership

- Terminating Your Own Program

- $\quad$ Utilizing Collaborative and Three-dimensional Imaging Technology

A complete listing and electronic copies of published research are available on our website: www.acquisitionresearch.org 
THIS PAGE INTENTIONALLY LEFT BLANK

MANPOWER, PERSONNEL, TRAINING \& EDUCATION RESEARCH GRADUATE SCHOOL OF BUSINESS \& PUBLIC POLICY NAVAL POSTGRADUATE SCHOOL 
MANPOWER, PERSONNEL, TRAINING \& EDUCATION RESEARCH GRADUATE SCHOOL OF BUSINESS \& PUBLIC POLICY NAVAL POSTGRADUATE SCHOOL 555 DYER ROAD, INGERSOLL HALL MONTEREY, CALIFORNIA 93943

www.acquisitionresearch.org 